This is the accepted version of the article:

Carné-Sánchez A., Carmona F.J., Kim C., Furukawa S.. Porous materials as carriers of gasotransmitters towards gas biology and therapeutic applications. Chemical Communications, (2020). 56. : 9750 - . 10.1039/d0cc03740k.

Available at: https://dx.doi.org/10.1039/d0cc03740k 


\title{
Porous materials as carriers of gasotransmitters towards gas biology and therapeutic applications
}

\author{
Arnau Carné-Sánchez, ${ }^{a, c}$ Francisco J. Carmona, ${ }^{a}$ Chiwon Kim, ${ }^{a, b}$ Shuhei Furukawa, ${ }^{a, b *}$ \\ The discovery of $\mathrm{NO}, \mathrm{CO}$, and $\mathrm{H}_{2} \mathrm{~S}$ as gasotransmitters and their beneficial role in multiple physiological functions opened an \\ era of research devoted to exogenously deliver them as therapeutic agents. However, the gaseous nature of these molecules \\ demands new forms of administration that enable to control the location, dosage and timing of their delivery. Porous \\ materials are among the most suitable scaffolds to store, deliver and release gasotranmistters due to their high surface area, \\ tunable composition and reactivity. This review highlights the strategies employed to load and release gasotransmitters \\ from different kinds of porous materials, including zeolites, mesoporous silica, metal-organic frameworks and protein \\ assemblies.
}

\section{Introduction}

Signaling molecules behave as messengers between cells, which trigger subsequent physiological and chemical transformations that are vital for the correct function of our organism. Among those, gaseous signaling molecules, also termed as gasotransmitters, represent a unique class of signaling molecules because their gaseous nature allows them to diffuse through cell membrane and to trigger a broad range of catalytic, metabolic processes within a short time after their release. To date, three main gasotransmitters have been identified: nitric oxide (NO), carbon monoxide (CO) and hydrogen sulphide $\left(\mathrm{H}_{2} \mathrm{~S}\right) \cdot{ }^{1-3}$ Chronologically, NO was the first gaseous molecule identified as a signaling molecule. In 1987 NO was identified as the endothelium-derived relaxing factor (EDRF) responsible for vein and artery dilation. ${ }^{4}$ Since then, the interest in the biological relevance of NO was increased and its biological synthesis from L-arginine by a family of enzymes named as NO synthases (NOS) was discovered. ${ }^{5}$ Unlike NO, the biosynthesis of $\mathrm{CO}$ from haem degradation catalysed by haem oxygenase (HO) was known long before and for a long time CO was considered as a toxic by-product of the metabolism. ${ }^{6}$ The discovery of the biological function of NO triggered a renovated research effort focused on the biological role of $\mathrm{CO}$. These efforts yielded the identification of $\mathrm{CO}$ as the second gasotransmitter with an important physiological impact in a variety of processes such as vasodilation, anti-inflammation, anti-proliferation and anti-apoptosis. ${ }^{7,8} \mathrm{H}_{2} \mathrm{~S}$ was included to the family of gasotransmitters in 2002 and is the last molecule added to this kind of signaling molecules thus far. The presence of $\mathrm{H}_{2} \mathrm{~S}$ in the organism was already described and, as in the case of $\mathrm{CO}$, its role was supposed to be as a merely noxious toxin. ${ }^{2}$ ENREF 9 Further research demonstrated that $\mathrm{H}_{2} \mathrm{~S}$ is involved in many intracellular signaling pathways with important functions in cytoprotection, anti-oxidation, vasodilation and angiogenesis. ${ }^{9,10}$

The beneficial effects of gasotransmitters in various physiological functions open the possibility to deliver them exogenously as therapeutic agents. However, all three gasotransmitters identified so far behave as a double-edged sword. They possess acute toxicity at high concentration while they present the therapeutic effects at low concentration. In addition, their activity is also dictated by where they are located. For instance, high accumulation of $\mathrm{CO}$ or NO in the lungs might result in oxygen replacement in heme and severe hypoxia. On the other hand, vasodilation is induced when these gases are released into blood vessels, which is an effective treatment against coronary diseases. Another example is provided by the anti-inflammatory effect of $\mathrm{CO}$ when delivered in the organs or tissue, which postulates $\mathrm{CO}$ as a promising nonsteroidal ant-inflammatory drug. ${ }^{11}$

In addition, their gaseous nature implies that challenges related with their handling, storage and appropriate delivery have to be overcome before considering the use of gasotransmitters as drugs. In this context, the use of scaffolds able to immobilize bioactive gas molecules in solid state (or in solution) and liberate them on demand is highly desirable. Molecules that release bioactive gases gradually or upon external stimuli have been extensively studied and excellent

\footnotetext{
a. Institute for Integrated Cell-Material Sciences (WPI-iCeMS), Kyoto University, Yoshida, Sakyo-ku, Kyoto, 606-8501, Japan

b. Department of Synthetic Chemistry and Biological Chemistry, Graduate School of Engineering, Kyoto University, Katsura, Nishikyo-ku, Kyoto, 615-8510, Japan

c. Catalan Institute of Nanoscience and Nanotechnology (ICN2), CSIC and Barcelona Institute of Science and Technology, Campus UAB, Bellaterra 08193, Barcelona, Spain.

+ Footnotes relating to the title and/or authors should appear here.

Electronic Supplementary Information (ESI) available: [details of any supplementary information available should be included here]. See DOI: 10.1039/x0xx00000x
} 
reviews are available. ${ }^{12-16}$ However, the fast diffusion of molecules once administrated limit the scope of this strategy as they may cause toxicity to untargeted healthy tissues either by the action of the liberated gasotransmitters or by the release of by-products after gas release. Thus, structuring of gasotransmitters into functional scaffolds in the solid state is a promising strategy to achieve higher payloads of the bioactive gas in targeted areas because they are easier to localize. To date, many kinds of solid-state materials are utilized to release bioactive gases such as inorganic and silica nanoparticles, ENREF 18 liposomes ENREF 18 and organic polymers. ${ }^{17-19}$ However, in most cases these materials lack from low payloads, which limits their releasing capacity. This is due to the fact that the surface of materials is only available for drug loading (through surface functionalization). A promising strategy to overcome this issue is to use porous materials as functional scaffolds. The high surface area that these materials possess enables to incorporate gasotransmitters not only on their material surfaces but also within the pores, which guarantees a higher drug loading. Thus, in this review the current advances on gasotransmitters loading, and release, in porous materials are surveyed including zeolites, mesoporous silica, metal-organic frameworks and protein assemblies.

\section{Strategies to load gases into porous materials}

To incorporate gasotransmitters or gas-donor molecules into porous materials one can chose among several strategies. However, the loading methodology will influence not only the loading efficiency but will also affect the rate of release and stimuli that will trigger the release. We categorized the existing methodologies to incorporate bioactive gases into porous materials as follows (Figure 1 );

(1) Use of open metal sites (OMSs) as binding moieties. All porous materials listed here can incorporate metal ions into scaffolds and expose an unsaturated coordination site on metal ions as an OMS. The three gasotransmitters, NO, $\mathrm{CO}$ and $\mathrm{H}_{2} \mathrm{~S}$, have a strong coordination capability to metal ions, and thus, can be anchored on the pore walls of materials containing OMSs.

(2) Use of the catalytic properties of the OMSs to trigger chemical reactions that produce gasotramsmitters as products. OMSs can not only be used as an anchoring site, but also as a catalytic site. In this case the porous material behaves similarly to an enzyme able to transform a donner molecule of gasotransmitters or known as a pro-drug into a gasotransmitter.

(3) Immobilization of donor molecules of gasotransmitters on the pores by post-synthetic modification. In this strategy, coordination or covalent bonds are often used to fix donor molecules on the pore walls after forming porous materials.

(4) Physical encapsulation of donor molecules of gasotransmitters in porous materials. By taking an advantage of porous materials, pro-drugs can be incorporated into the pores. However, due to the low host-guest interaction, the molecules can be leaked out of pores. Several strategies are available to limit the extent of the leakage and will be discussed in this review.

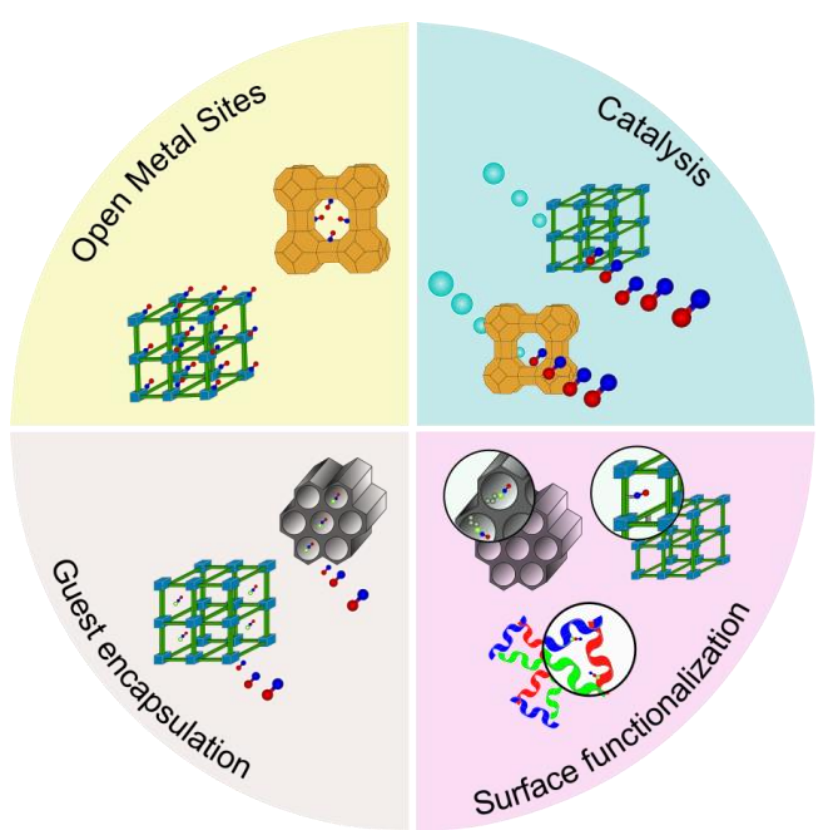

Figure 1: Scheme of the different strategies to prepare gasotransmitter-releasing materials based on porous frameworks. The existing combinations between strategy and porous framework are indicated. Nitric oxide molecule is used as a gas model.

\section{Zeolites}

Zeolites are a family of crystalline porous aluminosilicates with general formula $\mathrm{M}^{\mathrm{n}+}{ }_{\mathrm{x} / \mathrm{n}}\left[\left(\mathrm{AlO}_{2}\right)_{\mathrm{x}}\left(\mathrm{SiO}_{2}\right)_{\mathrm{y}}\right]^{\mathrm{x}}$. With their wellorganized and regular system of channels and pores, zeolites have been applied for ion exchange, catalysts and molecular sieves. ${ }^{20}$ The non-toxic behavior of zeolites combined with their molecular storage property based on microporosity provides an opportunity to be used as drug carriers. ${ }^{21}$ The presence of OMSs in zeolites, upon guest removal, is advantageous towards trapping and releasing gasotransmitters. Likewise, the inherent OMSs together with the feasibility of generating catalytic sites in their frameworks (e.g. acidic sites) could enable the production of gasotransmitters from bioavailable substrates. Even though one can find reports on the adsorption of $\mathrm{H}_{2} \mathrm{~S}$ and $\mathrm{CO}$ in zeolites, ${ }^{22,}{ }^{23}$ they are solely focused in their adsorption for removal application and not in their release for therapeutic applications. Therefore, in this section the loading and release of NO will be exclusively discussed.

\subsection{Coordination on open metal sites}

The inherent or post-synthetically generated OMSs in zeolites can act as anchoring points, where gasotransmitters can be coordinated. This induces a slower and more controlled release than when gasotransmitters are merely physisorbed.

Morris and co-workers demonstrated and quantified the high affinity of NO towards zeolites by means of gas sorption experiments. In these experiments, the Co-exchanged zeolite $A$ (Co-LTA) showed an uptake of $1.7 \mathrm{mmol} \mathrm{g}^{-1}$ at $800 \mathrm{mmHg}$. More interesting is the fact that $76 \%$ of NO was not released when the pressure was reduced, which demonstrated the strong 
a)

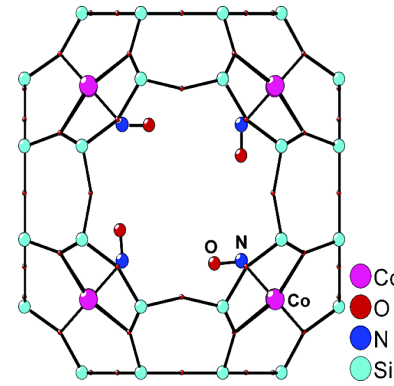

b)

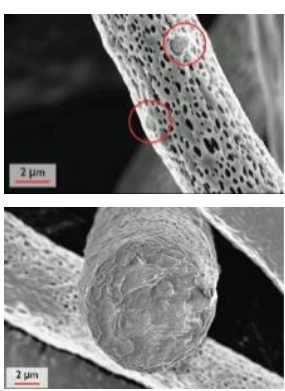

c)
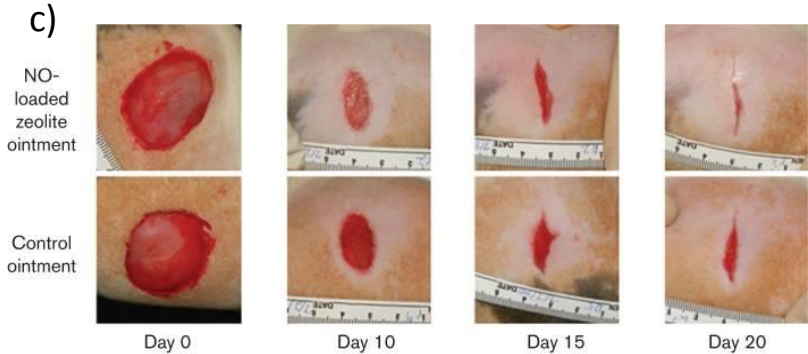

Day 20

Figure 2: NO-releasing systems prepared by the chemisorption of NO to open metal sites in zeolites and their beneficial effects: a) Structure of cobalt-NO complex in zeolite-A as elucidated by single-crystal X-ray diffraction. Reprinted with permission from Ref. 24. Copyright 2006 American Chemical Society. b) SEM images of electrospun polylactic acid fibers containing a $13 \%$ of cobalt-Zeolite $A$. The hybridization of the zeolite into a macroscale material allows to prepare humidity-triggered NO-releasing bandages with gradual gas release. Reprinted with permission from Ref. 25. Copyright 2009 American Chemical Society. c) enhanced wound-healing due to the topical application of an ointment containing a $33 \%$ of NO-loaded Zn-zeolite-A in comparison with the application of the pristine ointment Reprinted with permission from Ref. 27. Copyright 2014 Microbiology Society.

affinity of NO towards the OMSs present in the structure (Figure 2a). ${ }^{24}$ However, the release of NO could be triggered by water molecules, which have stronger affinity towards open metal sites than NO. Indeed, $1.0 \mathrm{mmol} \cdot \mathrm{g}^{-1}$ of NO was released from NO-loaded Co-LTA by flowing wet gas $(11 \%$ of relative humidity). In addition, the releasing kinetic could be tuned by varying the relative humidity of the wet gas. This degree of control of the NO delivery from the zeolite was exploited to probe the biological effect of exogenously delivered NO in cells by testing its inhibition in platelet aggregation. A key step towards the use of NO releasing materials in real world applications is their integration into shaped, easy-handling macroscopic materials. In this context, Balkus et al hybridized NO-loaded Co-LTA crystals with polymeric fibers of polylactic acid (PLA) with bandage shape (Figure $2 b$ ). ${ }^{25}$ Interestingly, the hybridization induced a more prolonged release by preventing water to come into contact with the dispersed crystals. Such hybrid nature offers the opportunity to attain additional control over the NO releasing rate.

Zeolites can be easily functionalized by exchanging with transition metal ions in their structure. Thus, in addition to CoLTA, other transition metal ion-exchanged LTA were evaluated as NO delivery vehicles, such as pristine LTA, nickel, ENREF 25 copper, manganese ${ }^{24}$ or ENREF 27 zinc $^{26}$. ENREF 29 This tunability in the zeolite composition has an impact on the maximum loading capacity, release kinetics and also the

appearance of synergistic effects. For example, the burst antibacterial effect of the NO-loaded Zn-LTA against Gramnegative and Gram-positive bacteria was coupled with the long lasting antibacterial effect of the slowly leached $\mathrm{Zn}$ (II) ions from the zeolite. Likewise, its hybridization with macroscopic materials could not only modulate the properties of the resulting materials, but also favor its development toward real applications. In this regard, Joshi et al., developed an ointment containing a $33 \%$ of NO-loaded Zn-LTA. ${ }^{27}$ The hybrid system showed a slower NO release than the pristine NO-zeolite, when suspended in phosphate buffered saline (PBS). The higher hydrophobic character of the ointment hindered the NOexchange with water molecules at the OMSs. This more sustained NO-release resulted in a significant microbicidal activity, and during longer times, against common wound pathogens. Likewise, the topical application of the hybrid ointment demonstrated to enhance the healing of cutaneous wounds in rats (Figure 2c). These examples bring to light the feasibility of modulating the release of bioactive agents from zeolites (NO, Zn(II) ions), which determines the biological response. They show the potential of NO-zeolites systems to be incorporated in wound dressing towards the treatment of infected wounds.

Beside the naturally occurring LTA-type of zeolites, titanosilicates have also shown their potential in storing and releasing NO. These materials possess stoichiometric amounts of OMSs in their structures, which, largely affect the adsorption and release of NO. Rocha and co-workers focused on the OMSs of titanosilicates, ETS-4 ([Na9 $\left.\left.\mathrm{Si}_{12} \mathrm{Ti}_{5} \mathrm{O}_{38}(\mathrm{OH}) \cdot \mathrm{xH}_{2} \mathrm{O}\right]\right)$, which are based on pentacoordinated Ti(IV). ${ }^{28}$ In order to systematically study the impact of the OMSs on the performance of titanosilicates, ETS-4 was compared with ETS-10 $\left.\left[(\mathrm{Na}, \mathrm{K})_{2} \mathrm{Si}_{5} \mathrm{TiO}_{13} \cdot \times \mathrm{H}_{2} \mathrm{O}\right]\right)$, which possesses only fully coordinated (hexacoordinated) Ti(IV). As expected, the uptake of ETS-4 largely outperformed ETS-10 ( 11 wt\% and 5.5\%, respectively). The further partial replacement of extraframeworks $\mathrm{Na}(\mathrm{I})$ cations by $\mathrm{Cu}(\mathrm{II})$ increased slightly the NO loading. However, the post-functionalization led to an increase in the toxicity of the material, probably because of the leaching of the extraframework copper cations. ${ }^{29}$ Accordingly, they explored the effects of the isomorphic substitution of framework silicium groups in ETS-10, by the less toxic $\mathrm{Al}(\mathrm{III})$ and $\mathrm{Ga}$ (III) cations. ${ }^{30}$ The exchanged materials offered higher NO payloads than the unexchanged ETS-10, due to the chemisorption of the gas to the exchanged cations, being also higher than the previous reported $\mathrm{Cu}(\mathrm{II})$-exchanged ETS-4. Furthermore, the Al- and Gaexchanged materials exhibited a significant lower toxicity than the Cu-ETS-4 analogs and no metal leaching was observed when incubated in cell culture medium. ${ }^{31}$ Although the properties of titanosilicates as NO-storing solids are promising, the assessment of their ability to regulate biological functions is essential toward their evolution to real therapeutic applications. With this aim in mind, Pinto and co-workers studied the biocompatibility, chemical stability and NO-release in biological medium of the above-mentioned materials. They selected unexchanged ETS-4 matrix as the most promising material in terms of amount and sustained NO-release, toxicity 
and stability. NO-loaded ETS-4 proved to elicit biological responses due to NO-release by reversibly inhibiting mitochondrial oxygen consumption in HeLa cells and promote cell migration, highlighting its potential application in wound healing. ${ }^{31}$

\subsection{Catalysis}

As explained in the previous section, great advances have been carried out on the develop of zeolites for storing and releasing NO towards therapeutic applications. However, this strategy shows two main drawbacks: $i)$ the stored gas is finite and only suitable for short-term applications and ii) the materials usually need to be conserved under special conditions (e.g. away from moisture). One alternative is the chemical production of the gas from a bioavailable substrate.

It is known that nitrite reductase enzymes in bacteria transform $\mathrm{NO}_{2}{ }^{-}$to $\mathrm{NO}$ mediated by $\mathrm{Cu}(\mathrm{I})$ metal sites. ${ }^{32}$ Based on this, Morris and co-workers prepared $\mathrm{Cu}$ (II)-Zeolite-X and $\mathrm{Cu}$ (II)ZSM- 5 by extraframework cation exchange. ${ }^{33}$ The thermal activation of the materials led to generation of $\mathrm{Cu}(\mathrm{I})$ sites by self-reduction reaction. ${ }^{34}$ Although the materials generated a significant amount of NO when suspended in nitrite aqueous solution, the NO production lasted only for few hours. The concurrent action of both water and dioxygen molecules led to the re-oxidation of the $\mathrm{Cu}(\mathrm{I})$ centers to $\mathrm{Cu}(\mathrm{II})$, inhibiting the further transformation of nitrites to NO. More interesting is the fact that the pre-adsorption of NO resulted in a constant production of NO during $10 \mathrm{~h}$. The exposition of the materials to gaseous nitric oxide results in the chemisorption of NO to the $\mathrm{Cu}(\mathrm{I})$ centers. In the presence of water, only a small fraction of the loaded NO is released, while the significant amount of NO is maintained in the material. The irreversibility of chemisorbed NO hindered the interaction between both water and dioxygen with the $\mathrm{Cu}(\mathrm{I})$ sites and inhibited their re-oxidation, and therefore, favoring the sustained conversion of nitrite to nitric oxide. This demonstrated the cooperative effect of NOadsorbed on the NO-production process.

The acidic transformation of nitrites is an alternative route to produce NO. Morris and co-workers studied the effect of the pore size of acidic zeolites on the production of NO from nitrites by testing four different zeolites: Al-UTL, AI-IPC-2, AI-IPC-4 and Al-IPC-6. To this end, they employed the ADOR (AssemblyDisassembly-Organization-Reassembly) method, ${ }^{35}$ which allows to selectively control the pore size of the zeolite by altering the linkers between silicate layers. They observed that the higher pore size, the larger amount of NO generated and the faster kinetics, demonstrating the feasibility of tuning the NOgeneration according to the targeted application. ${ }^{36}$ In another work, Morris et al. prepared several acidic and copperexchanged zeolites based on mordenite, ferrierite, ZSM-5 and SSZ-13. ${ }^{37}$ Although all materials were able to produce NO from nitrite sources, the copper-loaded materials showed a higher activity. In addition, given the known presence of cysteine in the body, the ability to generate NO of the materials in mixture of nitrite/cysteine at biologically relevant concentration was assessed. As the acidic sites were consumed during NOproduction, the continuous NO-generation after subsequent
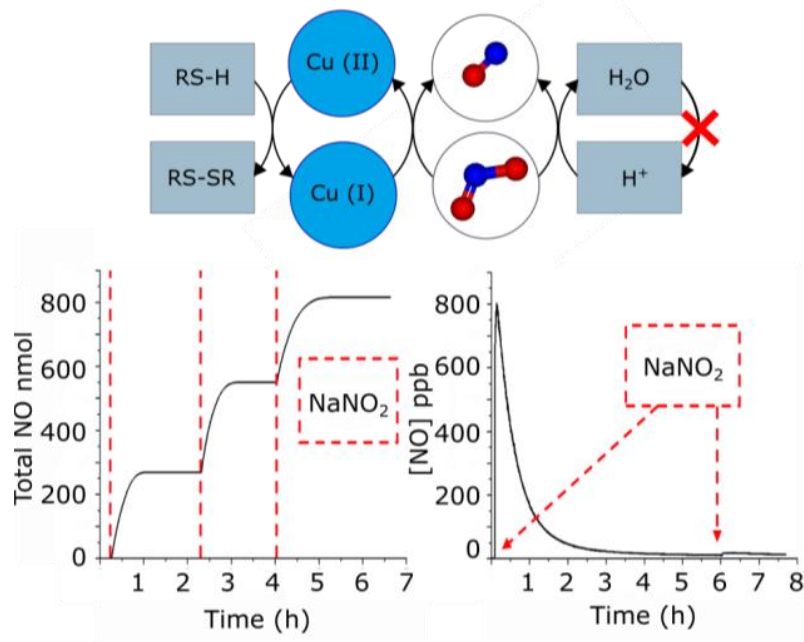

Figure 3: Scheme of the generation of NO from nitrites mediated by $\mathrm{Cu}(\mathrm{l})$ ions and acidic sites in zeolites. Bioavailable compounds like cysteine (RS-H) are able to regenerate the $\mathrm{Cu}(\mathrm{I})$ sites, allowing a continue release after the addition of substrate (e.g. $\mathrm{NaNO}_{2}$ ). In contrast, the acidic groups in zeolites are not regenerated. Therefore, the repeatedly addition of substrate does not result in a continue release of NO when the active sites are consumed. Adapted from Ref. 37 with permission from The Royal Society of Chemistry.

addition of substrate was inhibited. Conversely, the $\mathrm{Cu}(\mathrm{I})$ sites were regenerated by the oxidation of the cysteine present in the media, allowing the continuous conversion of nitrite (Figure 3). Among the different Cu-zeolites, $\mathrm{Cu}$-SSZ-13 shows the best biocompatibility, making it a promising zeolite to use in the body.

\section{Mesoporous silica}

Mesoporous silica are porous inorganic solids formed by amorphous silicon dioxide containing periodic arrays of channels and cavities. They have been widely used as drug delivery platforms due to their 2 to $50 \mathrm{~nm}$ pore size and biocompatibility. ${ }^{38}, 39$ Compared to zeolites (described in Section 3) that store gasotransmitters within their small cavities, mesoporosity offers new strategies to accommodate gasotransmitters. For example, one can encapsulate gas-donor molecules, much bigger than the gas itself, which can trigger the release of gasotransmitters by different stimuli such as light, heat or ultrasounds. This strategy can be enriched by the fact that the pore surface can be covalently modified by silanol chemistry. ${ }^{40}$ In the following sub-sections, representative works of these two strategies are summarized.

\subsection{Encapsulation of gas-donor molecules}

The encapsulation of molecules into the pore of mesoporous silica is basically driven by physisorption; the physical interaction between guest molecules and the pore surface of host materials. Consequently, encapsulated guest molecules can escape from the pores by diffusion due to the lack of strong chemical bonding. Therefore, the extent of leaching is the most important issue in this strategy.

To prevent the escape of guest molecules, Rickus and coworkers used liposome vesicles as capsule for NO donor 
molecules. ${ }^{41}$ Liposomes, phospholipid bilayer vesicles, are also

a)

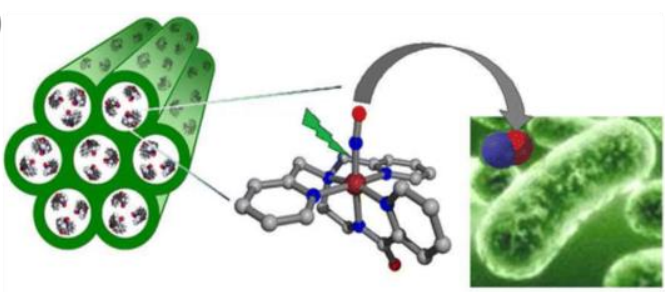

b)

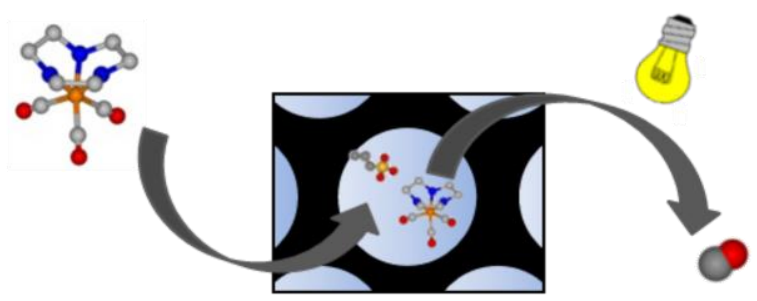

C)
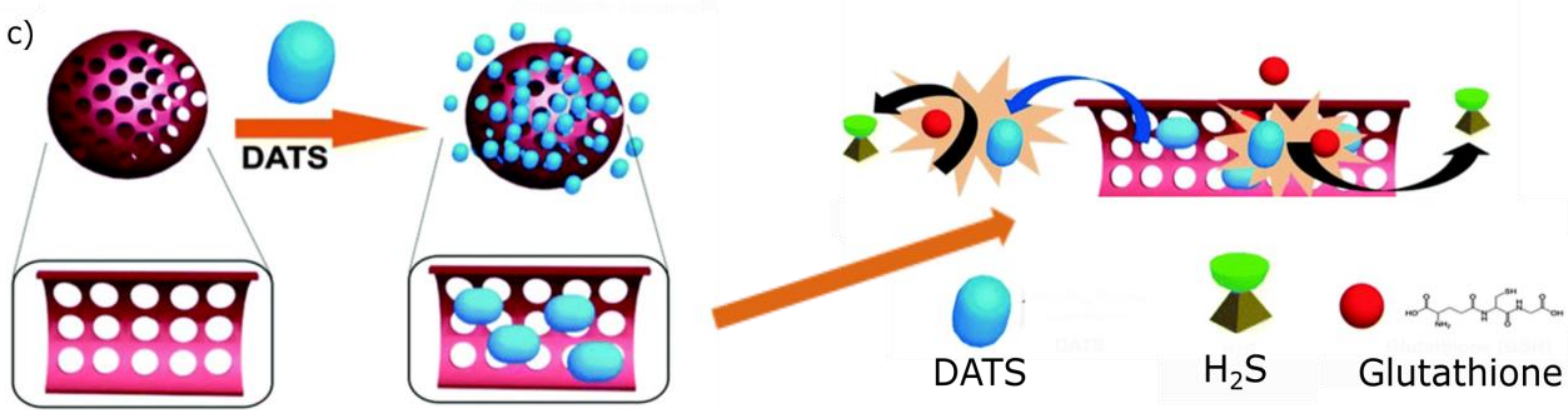

Figure 4: Gas-releasing frameworks prepared by the encapsulation of gas donors into the cavities of mesoporous silica. There exist examples of gas-donor@Mesoporous silica systems for all gasotransmitters (e.g. $\mathrm{CO}, \mathrm{NO}$ and $\mathrm{H}_{2} \mathrm{~S}$ ), demonstrating the high versatility of mesoporous silica to prepare gas-releasing materials by means of gas-donor encapsulation strategy. a) Representation of Al-MCM-41 mesoporous silica loading the cationic $\left[\mathrm{Mn}\left(\mathrm{PaPy}_{3}\right)(\mathrm{NO})\right]^{+}$complex. The irradiation with visible light elicits the NOrelease response, exerting an antibiotic effect against a skin pathogen (e.g. A. baumannii). Reprinted with permission from Ref. 47. Copyright 2012 American Chemical Society. b) Encapsulation of the cationic photoCORM $\left[\mathrm{Mn}(\operatorname{tacn})(\mathrm{CO})_{3}\right]^{+}$into mesoporous silicas functionalized with anionic sulfonic groups. The photoresponsive properties of the pristine CORM are maintained and the hybrid material release CO under photoactivation with visible light. Adapted with permission from Ref. 50 . Copyright 2016 American Chemical Society. c) Schematic representation of the encapsulation of Diallyl trisulfide (DATS) in a mesoporous silica. The interaction of DATS with the bioavailable glutatathione results in the release of $\mathrm{H}_{2} \mathrm{~S}$. The both slower diffusion of glutathione inside the pores and DATS outside the pores enable a more controlled release of $\mathrm{H}_{2} \mathrm{~S}$. Reproduced from Ref. 55 with permission from The Royal Society of Chemistry.

widely used as drug nanocarriers because they prevent the

leaching of the entrapped molecule. ${ }^{42,} 43 \mathrm{~S}$-nitroso- $N$ acetylpenicillamine (SNAP), which is known to be a lightinduced NO donor molecule was encapsulated into liposomes, followed by doping them into the synthetic solution of the mesoporous silica. The sol-gel reaction of this mixture containing SNAP, liposomes and tetraethyl orthosilicate (TEOS) provided the liposome/mesoporous silica composite materials. Therefore, the NO release from the functional substrate was measured by implementing a self-referencing amperometric NO microsensor. It was found that the evolution of NO from the mesoporous silica surface was dependent on light irradiation and was within the range of biological relevance $\left(14 \mathrm{pmol} \cdot \mathrm{cm}^{-}\right.$ 2. $\left.\mathrm{sec}^{-1}\right) .{ }^{44}$ In addition, the mesoporous silica composite could be used as a functional growth surface for mammalian cells. ${ }^{45,46}$

Mascharak and co-workers attempted to limit the leaching of NO donor molecules by using host-guest electrostatic interactions. ${ }^{47}$ Thus, they compared the uptake amount of the positively charged metal-nitrosyl NO donor complex $\left(\left[\mathrm{Mn}\left(\mathrm{PaPy}_{3}\right)(\mathrm{NO})\right] \mathrm{ClO}_{4}\right.$, denote as $\left.\mathrm{Mn}-\mathrm{NO}\right)$ into a negatively charged aluminosilicate mesoporous material (denote as AlMCM-41), and neutral mesoporous silica material (Si-MCM-41). Al-MCM-41 showed a $20 \%$ higher uptake when compared to SiMCM-41 (Al-MCM-41: 2.39 wt.\%, Si-MCM-41: 2.04 wt.\%,). In addition, Al-MCM-41 showed less leaching of Mn-NO than Si-
MCM-41 in saline solution after $24 \mathrm{~h}$ incubation $(2.92 \%$ and $3.44 \%$ of adsorbed Mn-NO were leached from Al-MCM-41 and Si-MCM-41, respectively). The mechanism of $\mathrm{Mn}-\mathrm{NO}$ loading into Al-MCM-41 was supposed to entail cation exchange between $\left[\mathrm{Mn}\left(\mathrm{PaPy}_{3}\right)(\mathrm{NO})\right]^{+}$and $\mathrm{Na}(\mathrm{I})$ ions inside the host and passive diffusion. On the other hand, passive diffusion was the only driving force for $\mathrm{Mn}-\mathrm{NO}$ loading into Si-MCM-41. Congruent with the higher loading capacity of Al-MCM-41, its releasing amount of $\mathrm{NO}$ by light irradiation was also higher than Si-MCM-41 (0.43 mmol g ${ }^{-1}$ for Al-MCM-41 and $0.30 \mathrm{mmol} \mathrm{g}^{-1}$ for $\mathrm{Si}-\mathrm{MCM}-41)$. The control on NO release from Al-MCM-41 allowed studying its antibiotic effect on $A$. baumannii, $a$ skin and soft-tissue infections (SSTI) model showing effective clearance upon light-triggered NO release (Figure 4a).

Zhao and co-workers took an advantage of the porosity of mesoporous silica to accommodate a photolytic NO-donor $\left(\left[\mathrm{NH}_{4}\right]\left[\mathrm{Fe}_{4} \mathrm{~S}_{3}(\mathrm{NO})_{7}\right]\right.$, Roussin's Black Salt) in a core-shell upconversion nanoparticle@mesoporous silica nanocomposite. 48 The irradiation of the nanoparticles with low-damage nearinfrared irradiation $(\lambda=980 \mathrm{~nm}$, within of the therapeutic window) activated the NO-release, being only possible for the bare NO-donor under higher energetic irradiation. By modulating the laser output power, the amount of gas generated was controlled, resulting in a dose-controlled NO- 
release systems. This feature was later demonstrated by in vitro cell studies, where different biological responses with NO-dose dependence were achieved by simply tuning the power irradiation of the NIR light used as a trigger.

Mesoporous silica can also be employed as vehicles to transport guest drugs to the targeted tissue. In addition, the extent of the leaching of the encapsulated NO-prodrug could enable a more sustained NO-release. This strategy was employed by Deng et al. toward the efficient treatment of Primary Open-Angle Glaucoma (POAG). ${ }^{49}$ Nitric oxide has proved to reduce elevated intraocular pressure (IOP), a strong risk factor for developing POAG. Likewise, sodium nitroprusside (SNP), a N-donor, has been proposed as potential therapeutic agent against this disease. However, its low uptake through the cornea together with its poor stability limit its practical use. The encapsulation of SNP inside mesoporous silica resulted in a slower release of the $\mathrm{N}$-donor in PBS, extended during 50 hours. In vivo studies on Cav1 gene knockout mice demonstrated that SNP@mesoporous silica nanoparticles were able to go through cornea and reach the target tissues. In addition, the topical eye drop application of SNP@mesoporous silica (0.004 mg of SNP) resulted in IOP reduction of $22 \%$ after $3.5 \mathrm{~h}$, followed by a sustained IOP reduction during $48 \mathrm{~h}$. On the contrary, the dose of the same amount of SNP solution did not affect IOP, demonstrating the beneficial effect of NO-donor encapsulation.

CO-prodrugs, known as CO-releasing molecules (CORMs), have also been incorporated into the cavities of mesoporous silica to generate CO-releasing materials. For instance, Barea and co-workers functionalized the pore surface of MCM-41 and SBA-15 mesoporous silica with alkanesulfonic groups to confer an anionic character to the frameworks. By cation exchange, they successfully encapsulated the cationic photoactive $\mathrm{CO}$ releasing molecule (photoCORM) $\left[\mathrm{Mn}(\operatorname{tacn})(\mathrm{CO})_{3}\right]^{+}$(where tacn is 1,4,7-triazacyclononane), which could not be encapsulated into the neutral matrices (Figure 4b). Both hybrid materials kept the photoactivity of the pristine CORM, but offering a more sustained CO-delivery kinetics in physiological media when irradiated with white light. Unfortunately, the host-guest interactions were not strong enough and led to partial leaching of the cationic CORM when incubated in saline buffer. ${ }^{50}$

As it was done with the NO-donor $\left(\left[\mathrm{Mn}\left(\mathrm{PaPy}_{3}\right)(\mathrm{NO})\right] \mathrm{ClO}_{4}\right.$, Mascharak et al. also used the cation exchange strategy to incorporate a cationic photoCORM into the negatively charged Al-MCM-41 nanoparticles (approx. $60 \mathrm{~nm}$ ). ${ }^{51}$ For this, the manganese carbonyl complex $\left(\mathrm{fac}-\left[\mathrm{Mn}(\mathrm{pqa})(\mathrm{CO})_{3}\right]^{+}\right.$, pqa $=(2-$ pyridylmethyl)(2-quinolylmethyl)amine), denote as $\mathrm{Mn}-\mathrm{CO}$, was exchanged with the $\mathrm{Na}(\mathrm{I})$ ions presenting in the initial Al-MCM41 structure. In this case, the host-guest electrostatic interactions ensured a small percentage of leaching when the composite was incubated in PBS (i. e. $2 \%$ and $12 \%$ of $\mathrm{Mn}(\mathrm{I})$ leaching after incubating for $24 \mathrm{~h}$ and $60 \mathrm{~h}$, respectively). The released CO from the [Mn-CO]@AI-MCM-41 nanoparticles upon light irradiation was used to induce vasorelaxation of rat aorta muscle rings. A similar strategy was employed to incorporate the luminescent photoCORM $\left[\operatorname{Re}(\mathrm{CO})_{3}(\mathrm{pbt})\left(\mathrm{PPh}_{3}\right)\right]$, pbt $=2$-(2-pyridyl)-benzothiazole) into the pores of Al-MCM41.52 In this case, not only the intracellular delivery of biologically relevant amounts of $\mathrm{CO}$ was demonstrated, but also the nanoparticles could be easily tracked inside the cells, thanks to their inherent luminescence. The good encapsulating features of the anionic Al-MCM-41, its stability in physiological media and its large pores were exploited by Barea and coworkers to encapsulate both photoCORM $\left[\mathrm{Mn}(\operatorname{tacn})(\mathrm{CO})_{3}\right]^{+}$and cisplatin within the same carrier, suggesting the possibility of producing $\mathrm{CO}$ releasing solid platforms with multiple therapeutic effects. ${ }^{53}$ Diallyl trisulfide (DATS) is known as glutathione (GSH)-triggered $\mathrm{H}_{2} \mathrm{~S}$ donor, however, its fast releasing kinetics hinders its therapeutic use as a rapid increase of $\mathrm{H}_{2} \mathrm{~S}$ concentration may cause adverse effects in the metabolism. ${ }^{54}$ Wang and co-workers encapsulated DATS inside mesoporous silica nanoparticles in order to control the release kinetics of $\mathrm{H}_{2} \mathrm{~S}$ (Figure 4c). ${ }^{55}$ DATS was loaded into mesoporous silica nanoparticles (MSNs) by stirring mixture of DATS, MSNs and distilled water for $12 \mathrm{~h}$. Surprisingly, $99 \%$ of DATS molecules were encapsulated into MSNs (which accounts for a loading of $2.5 \mathrm{mmolg}^{-1}$ ). This very high loading indicates that there is a strong interaction between DATS and $\mathrm{Si}-\mathrm{OH}$ of MSNs surface. The low leaching (less than 10\%) observed upon 24h incubation in PBS further supported this hypothesis. The $\mathrm{H}_{2} \mathrm{~S}$ releasing experiments performed in the presence of GSH showed slower release kinetics from the composite nanoparticles in comparison with free DATS. The biomedical applications of the DATS-MSN nanoparticles were demonstrated by injecting them into mouse's veins. The nanoparticles effectively released $\mathrm{H}_{2} \mathrm{~S}$ into vein without causing any of the adverse effects caused by high concentration of $\mathrm{H}_{2} \mathrm{~S}$ (such as an increase in blood pressure and heart beat rate). Later, the same group demonstrated that the hybrid system DATS@MSNs promoted the proliferation and differentiation of endothelial cells in vitro and alleviated inflammatory response caused by hypoxia-reoxygenation. Likewise, in vivo studies in mouse models confirming these benefits, showing that DATS@MSN was able to protect the endothelium of aortic allografts from ischemia-reperfusion injurie. ${ }^{56}$

\subsection{Chemical attachment of gas donors}

The diversity of chemical functionalities that one can use in the sol-gel process (amine, hydroxyl and carboxylate among others) enables to functionalize mesoporous silica through postsynthetic reactions. One can use this chemistry to covalently attach donor molecules of gasotransmitter on the surface of these materials. This approach has the disadvantage that generally requires multi step chemical reaction. On the other hand, it reduces the extent of leaching due to the covalent interaction between the donor and the surface of the mesoporous silica.

Surface modification of mesoporous silica with coordination complexes has been researched by a number of groups in the late 1990 s and early 2000 s. ${ }^{57,} 58$ Since then, surface modified fumed silica, silica gel and silica nanoparticles have been extensively developed and applied to the field of gas biology. ${ }^{59-}$ 61 Longhinotti et al. immobilized cis-[Ru(bpy) ${ }_{2}(\mathrm{~L}) \mathrm{NO}^{3+}$ and $\left[\mathrm{Fe}(\mathrm{CN})_{4}(\mathrm{~L}) \mathrm{NO}\right]^{-}$complexes on surface functionalized mesoporous silica. ${ }^{62}$ The procedure entailed four sequential surface functionalization reactions, including amine functionalized mesoporous silica (Si-APTS), amine terminal 
converted to isonicotinamide (ISN) and $\mathrm{Ru}$ (II) and Fe(II) metal complexes immobilization on the surface of Si-APTS-ISN by reacting the functionalized silica with cis-[Ru(bpy $\left.{ }_{2} \mathrm{Cl}_{2}\right]$ and $\mathrm{Na}_{2}\left[\mathrm{Fe}(\mathrm{CN})_{4}(\mathrm{dmsO})_{2}\right]$ respectively. Finally, metal-nitrosyl functionalities were introduced by bubbling of NO gas to the prepared silica materials in acetone. Light-induced release of $\mathrm{NO}$ in the PBS from both of the prepared materials was estimated to be $1.8 \mathrm{mmol} \mathrm{g}^{-1}$.

An alternative moiety being able to store and deliver NO are the amine groups, which can store NO in the form of nitrite and release it under acidic conditions. To immobilize the amine functionality on the surface of mesoporous silica, $\gamma^{-}$ aminopropyltriethoxysilane (APTES) was attached on the surface of MCM-41 and mesoporous MFI zeolite, ${ }^{63}$ which was synthesized from MCM-41 by dry-gel conversion. ${ }^{64}$ Before the modification of APTES, NO was loaded on MCM-41 and MFI zeolite. which released 0.77 and $0.67 \mu \mathrm{mol} \cdot \mathrm{g}^{-1}$ of $\mathrm{NO}$ in the acidic aqueous solution, respectively. In contrast, APTES modified MCM-41 and MFI zeolite showed a release of 27.43 and $17.99 \mu \mathrm{mol} \cdot \mathrm{g}^{-1}$, respectively. The higher release observed in the case of MCM-41 is attributed to its higher surface area, which implies higher degree of surface functionalization. This high releasing amount in acidic conditions postulates these functionalized materials as efficient NO delivery vehicles for the gastrointestinal organs. The functionalization of the porous framework of mesoporous silica with aminosilanes was also employed by Schoenfisch et al. to generate novel NO-releasing materials. ${ }^{65}$ They prepared mesoporous silica with different particle size (ranging from 30 to $1100 \mathrm{~nm}$ ) and functionalized covalently the pores with terminal secondary amines. By reacting with NO, they were transformed in $\mathrm{N}$ diazeniumdiolates able to release NO in physiological media. The materials showed different NO-payloads and release kinetics in PBS. However, these differences could not be correlated with the distinct particle size of the carriers. A further analysis by powder small-angle X-ray scattering (SAXS) suggested that the different pore structure found in the functionalized systems determined these features. While more ordered pore system enhanced the diffusion of water through the cavities, resulting in faster NO-release kinetics, more heterogenous pore structures hindered the solvent diffusion and resulted in more sustained NO-release profiles. In another work, ${ }^{66}$ the amine groups in the outer surface of a $\mathrm{NH}_{2}-$ functionalized mesoporous silica were used to covalently attach erythrosine, a singlet oxygen photosensitizer (PS), while the internal surfaces were used to conjugate a nitro anilinederivative as a photoactive NO-donor. The antitumoral drug doxorubicin (Dox) was further encapsulated into the porous matrix, generating a multidrug carrier. In vitro studies on melanoma A375 cell line showed that, under light irradiation, the triple-drug nanomaterial exhibited a higher cytotoxicity than the dual system Dox-PS@mesoporous silica, suggesting an increased activity due to the nitric oxide release. A similar strategy was used to confer NO-releasing functionalities to a fluorescent carbon dot@mesoporous silica nanocomposites.67 The conjugation of a nitro aniline-derivative photo NO-donor to the pore surface quenched the emission from carbon dots by means of the Förster resonance energy transfer (FRET) process. More interestingly, the visible light irradiation triggered the NOrelease, with the concomitant fluorescence restoration of the carbon dots. Therefore, the nanocomposites showed a dualfunction, because they not only enabled a controlled NOrelease under light irradiation, but also counted with a fluorescence reporter, allowing the tracking of the gas delivery process by fluorescence spectroscopy.

S-nitrosothiols (RSNO), a kind of heat-sensitive NO-donor, has been also incorporated in mesoporous silica by surface functionalization. The feasibility of functionalizing mesoporous silica with thiol-terminated organosilanes was used by MalonePovolny and Schoenfisch for, subsequently, generating the Snitrosothiol sites. ${ }^{68}$ The same procedure was performed on nonporous silica nanoparticles to assess the influence of porosity on the NO-release kinetics. While the non-porous materials showed a half-life $\left(t_{1 / 2}\right)$ of NO release of $2.92 \mathrm{~h}$ in PBS at $37 \stackrel{\circ}{\circ}$, mesoporous silica particles exhibited a much more sustained release $\left(t_{1 / 2}\right.$ of $\left.26.6 \mathrm{~h}\right)$. These differences were explained by the "cage effect" shown by the porous material. The confined microenvironment in the nanometer-scale pores favored the recombination of the thiyl and NO radical pair after the homolytic cleavage of the S-N bond, extending the duration of NO delivery. They also dispersed the mesoporous nanoparticles in several polyurethane membranes towards their potential applications as coating of medical devices. Note that the nanocomposites exhibited a much longer prolonged NO-release (until 30 days), with negligible particle leaching after suspension in PBS for 21 days.
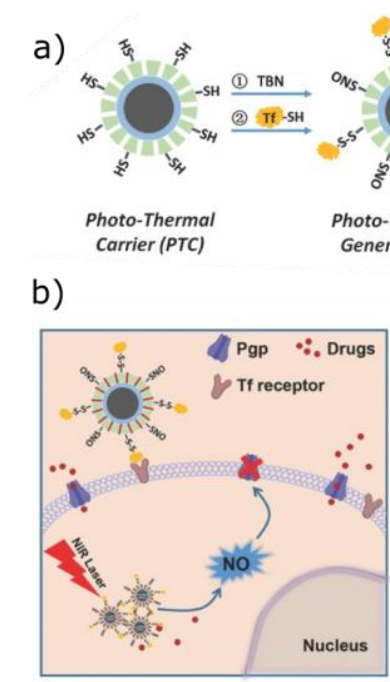

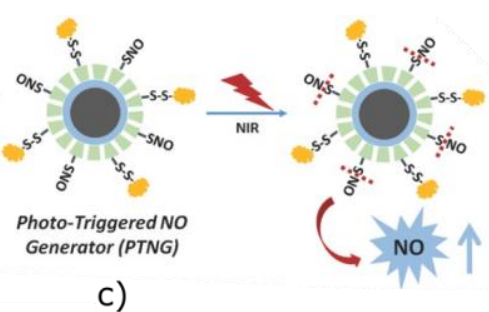

c)

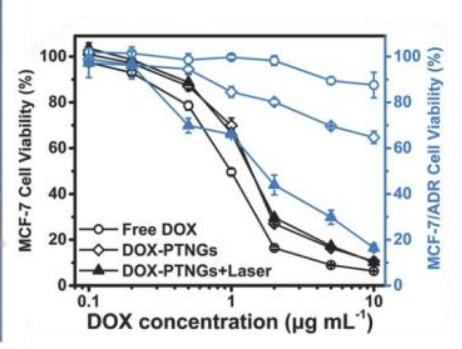

Figure 5: Core-shell $\mathrm{Fe}_{3} \mathrm{O}_{4} @$ Mesoporous Silica nanocomposite with photoresponsive antitumoral properties: a) Scheme of the generation of Snitrothiols and S-transferring in the mesoporous silica shell and of the photothermal responsive release of nitric oxide under near-infrared irradiation, b) and c) Antitumoral mechanism of the nanocomposite. The presence of transferring increases the specificity of the system toward tumoral-cells while the NIR irradiation activates the NO-release. Likewise, the NO-released exerts a signaling function, favoring the accumulation of doxorubicin in the cells, resulting in a high antitumoral activity against Multidrug Resistant cancer. Reprinted with permission from Ref. 69. Copyright 2017 John Wiley \& Sons, Inc. 
In another work, the terminate-thiol groups where used for both generating S-nitrosothiols and conjugating S-transferring (a cancer-cell targeting group) on a core-shell $\mathrm{Fe}_{3} \mathrm{O}_{4} @$ mesoporous silica nanocomposite (Figure 5a). The antitumoral drug doxorubicin was encapsulated into the cavities of mesoporous shell, generating a multidrug carrier. ${ }^{69}$ The nanocomposite was able to convert near-infrared irradiation into heat, enabling to trigger the NO-release by photoactivation. Remarkably, the concomitant release of doxorubicin and NO, triggered by NIR photoactivation for $5 \mathrm{~min}$, showed a synergistic effect toward the reduction of the cellviability of multidrug resistant breast cancer cell-line (MDRMCF-7) (Figures $5 b$ and $5 c$ ). In vivo studies on MCF-7/ADR tumor-bearing BALB/c nude mice confirmed these results. The treatment with the multifunctional nanocomposite and NIR showed a significant tumor inhibition, superior than the parallel treatments with the pristine drugs.

\section{Metal-organic frameworks}

Metal-organic frameworks (MOFs), also called as porous coordination polymers (PCPs), which are constructed via the assembly of metal ions with organic linkers, are receiving considerable attentions due to their structural characteristics, highly ordered microporosity, large surface area, and the wide range of potential applications in gas storage, gas separation, catalysis and sensors. ${ }^{70-72}$ Recently, by taking advantages of MOFs' porosity, researchers have used these materials in biomedical applications, in particular to store and release drug molecules. ${ }^{73}$ Compared to other porous materials introduced above, the most characteristic feature of MOFs is their inherent inorganic-organic hybrid nature, which enables to design and synthesize a virtually unlimited number of structures by appropriate combination of metal ions and organic linkers. Furthermore, the inherent hybrid nature of MOFs provides an opportunity to expand the possible strategies towards gasotransmitter delivery either by taking advantage of the inorganic part (i. e. OMSs, catalysis) or the organic part (i. e. post-synthetic modifications, prodrug ligands) or both parts acting synergistically. Their inherent porosity can be also used to host gas-donor molecules. Thus, the release of gasotransmitters from MOFs has been achieved by four characteristic strategies; (1) the release of coordinating gas molecules at open metal sites by exchanging with water molecules, (2) the catalytic decomposition of gas precursors at open metal sites, (3) encapsulation of gas-donor molecules inside their cavities and (4) incorporation of organic ligands within the MOF structure with the ability to adsorb and release gasotransmitters, or being themselves gasotransmitter donor moieties that can be activated upon external stimuli.

\subsection{Coordination on open metal sites}

The presence of OMSs decorating the pores of MOFs have shown great potential for selectively adsorb molecules with lone pair electron and, as in the case of zeolites, they can be used to store and release gasotransmitters. ${ }^{74}$
Morris and co-workers were pioneers in exploiting the OMSs in MOFs to incorporate NO. ${ }^{75}$ In the first study, $\left[\mathrm{Cu}_{3}(\mathrm{btc})_{2}\right]_{\mathrm{n}}$ (btc $=1,3,5$-benzentricarboxylic acid, also known as HKUST-1), which has Cu(II) OMSs, was used. The first evidence of Cu-NO coordination was provided by the NO sorption isotherms. These isotherms were characterized by a hysteresis in the desorption branch. The number of $\mathrm{NO}$ molecules that were not desorbed corresponded to the predicted number of OMSs in the HKUST-1 structure (i. e. $2.21 \mathrm{mmol} \cdot \mathrm{g}^{-1}$ ). Further evidences were provided by infrared spectroscopy performed in the NO-loaded HKUST-1, which showed the characteristic peak at $1887 \mathrm{~cm}^{-1}$ corresponding to the stretching vibration mode of NO coordinating to $\mathrm{Cu}(\mathrm{II})$ ions. The release of NO was triggered by treating the sample with water vapor, similar to the case of zeolites described in Section 3. However, a moderate release of $2 \mu \mathrm{mol} \cdot \mathrm{g}^{-1}$ corresponding to $0.1 \%$ of the initially adsorbed NO was found. The low NO release is rationalized by the strong coordination of the Cu-NO bond. Despite the low releasing efficiency, the release amount was enough to inhibit platelet aggregation confirming the potential of MOFs in the field of gasotransmitters release.

Suitable coordination strength between metal and NO is a key factor to obtain a material that performs well over the whole adsorption-storage-delivery cycle. In order to study the influence of the transition metal ions on the NO release, the same research group employed isostructural MOFs containing different metal ions in the adsorption/release of NO. Namely, they used $\left[\mathrm{Ni}_{2} \text { (dobdc) }\right]_{n}$ (denote as $\mathrm{CPO}-27-\mathrm{Ni}$, dobdc $=2,5-$ dioxido-1,4-benzenedicarboxylate) and $\left[\mathrm{CO}_{2}(\text { dobdc) }]_{n}\right.$ (denote as $\mathrm{CPO}-27-\mathrm{Co}$ ) for $\mathrm{NO}$ storage and delivery (Figure 6a). ${ }^{76} \mathrm{CPO}-$ 27-Ni and CPO-27-Co showed the total NO uptake of $7 \mathrm{mmol} \cdot \mathrm{g}^{-}$ 1 and $6 \mathrm{mmol} \cdot \mathrm{g}^{-1}$, respectively, at $25^{\circ} \mathrm{C}$ and $6 \mathrm{mmol} \cdot \mathrm{g}^{-1}$ and 5 $\mathrm{mmol} \cdot \mathrm{g}^{-1}$, respectively, of hysteresis in the desorption branch, which correspond to the number of OMSs in each structure. These results indicate that most of NO was adsorbed through coordination to the OMSs and approximately $1 \mathrm{mmol} \cdot \mathrm{g}^{-1}$ of $\mathrm{NO}$ was physically adsorbed into frameworks. Crystal structures of both frameworks ${ }^{77}$ clearly show that $\mathrm{NO}$ is coordinated to metal site with a bent geometry, which corresponds to NO acting as a one-electron donor. NO releasing from CPO-27-Ni and CPO-27Co was triggered by wet gas ( $11 \%$ relative humidity). Unlike the HKUST-1, these two MOFs released practically the same amount of $\mathrm{NO}$ as previously adsorbed. It is noteworthy that a NO releasing capacity of $7 \mathrm{mmol} \mathrm{g}^{-1}$ is the highest reported value for porous materials thus far. In order to test the biomedical applications of these materials, the vasodilation of precontracted pig coronary arteries induced by NO-loaded CPO-27$\mathrm{Ni}$ was tested. The results showed a rapid relaxation of pig coronary arteries immediately after exposing it to an aqueous suspension containing pellets of CPO-27-Ni.

The possibility to synthesize $\mathrm{CPO}-27$ analogue structures with different divalent metal ions enabled to systematically study the effect of the nature of the OMSs on the adsorption and release of NO. ${ }^{78}$ Long and co-workers reported the NO loading and releasing properties of CPO-27-Fe (based on $\mathrm{Fe}(\mathrm{II})) .{ }^{79}$ Interestingly, while the loading capacity was similar to the examples shown above (i.e. $6 \mathrm{mmol} \mathrm{g}^{-1}$ ), the releasing 
profile was different, showing an initial burst release followed by a slow and sustained release of NO that occurs over the course of 10 days. These results further prove the key role of the OMSs in the loading and releasing profiles of NO.

A unique feature of MOFs is that they combine OMSs with tunable microporosity. Therefore, one can take an advantage of these properties to design multifunctional carriers, delivering more than one substance. Barea and co-workers explored this strategy using $\mathrm{CPO}-27-\mathrm{Ni}$ as the host structure. ${ }^{80}$ First, the metallodrug with antitumor activity RAPTA-C ([Ru(pcymene) $\mathrm{Cl}_{2}$ (pta)], pta $=$ 1,3,5-triaza-7-phosphaadamantane) was introduce into the pores of the framework by physisorption. Subsequently, NO was loaded into the composite material. Interestingly, the NO loading capacity $\left(6 \mathrm{mmol} \cdot \mathrm{g}^{-1}\right)$ remained almost unaltered after the incorporation of RAPTA-c, which indicates that the coordination of NO at the OMSs of the framework was not influenced by incorporated RAPTA-C molecules. Importantly, the release of both bioactive molecules was very similar as in the case in which only one of the molecules was encapsulated, indicating the potential use of MOFs as multi drug delivery vehicles.

One of the key aspects when considering MOFs for biomedical applications is their toxicity both in vivo and in vitro. ${ }^{81}$ Therefore, the synthesis of MOFs with gasotransmitter releasing properties with non-toxic building blocks is a

a)

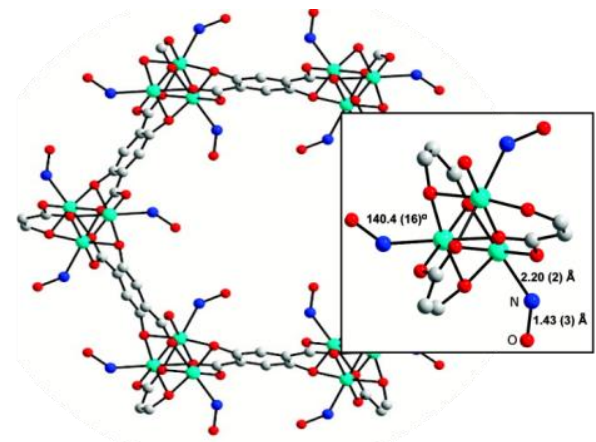

b)

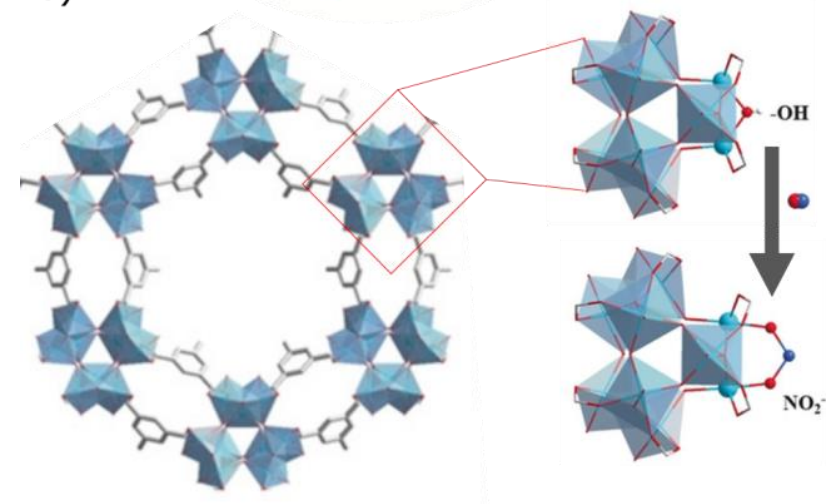

Figure 6: Examples of NO-releasing metal-organic frameworks showing open metal sites. a) Crystal structure of $\left[\mathrm{Co}\left(\mathrm{C}_{8} \mathrm{H}_{2} \mathrm{O}_{6}\right)(\mathrm{NO})_{2}\right]$ MOF prepared by the chemisorption of nitric oxide to the unsaturated-cobalt sites. In detail, the view of NO bound to the cobalt atoms in the MOF structure Reprinted with permission from Ref. 76. Copyright 2008 American Chemical Society, b) Schematic representation of the of the formation of chemisorbed nitrates on the titaniumbased $\mathrm{MOF} \mathrm{Ti}_{12} \mathrm{O}_{15}(\mathrm{mdip})_{3}(\mathrm{OH})_{6}(\mathrm{H} 2 \mathrm{O})_{6}$. Reprinted with permission from Ref. 86 Copyright 2020 John Wiley \& Sons, Inc. promising strategy to make these materials more biocompatible. The MIL- 88 series of MOFs composed by iron(III) carboxylates combine a non-toxic behaviour and the presence of OMSs, which can be used to capture NO. ${ }^{82}$ Therefore, they are suitable candidates as bio-friendly NO delivery vehicles. Serre and co-workers systematically studied the NO loading/release properties of these materials by synthesizing them with different functionalities $\left(\left[\mathrm{Fe}_{3} \mathrm{OX}\left(-\mathrm{O}_{2} \mathrm{C}-\mathrm{R}-\mathrm{CO}_{2}-\right)_{3}\right]_{n}, \mathrm{R}\right.$ $=$ terephtalic acid, fumaric acid, 2-nitroterephtalic acid and dobdc, ; $\mathrm{X}=\mathrm{F}, \mathrm{OH}, \mathrm{Cl}$ or $\left.-\mathrm{O}_{2} \mathrm{C}-\mathrm{CH}_{3}\right) .{ }^{83}$ The uptake in all cases fell between 1 and $2.5 \mathrm{mmol} \cdot \mathrm{g}^{-1}$. However, the release amount was limited in the range of $0.1 \mathrm{mmol} \cdot \mathrm{g}^{-1}$ due to the narrow pores in the structure and the strong binding of Fe-NO. In order to improve the NO releasing capacity of the $\mathrm{Fe}(\mathrm{III})$ based frameworks, the performance of Fe-MIL-100 $\left(\mathrm{Fe}_{3} \mathrm{OX}[\mathrm{btc}]_{2} . \mathrm{XH}_{2} \mathrm{O}\right)$, which contains big mesoporous cavities within its structure, was evaluated. As expected, the releasing efficiency was improved when compared to the MIL-88 structure releasing up to $15 \%$ of the initially chemisorbed NO $\left(0.35 \mathrm{mmol} \mathrm{g}^{-1}\right)$ over the course of $7 \mathrm{~h} .{ }^{84} \mathrm{In}$ this regard, the MOF bioMIL-3 [Ca 2 (azbz-TC)( $\left.\mathrm{H}_{2} \mathrm{O}\right)(\mathrm{DMF}), \quad$ azbc-TC $=3,3^{\prime}, 5,5^{\prime}-$ azobenzenetetracarboxylate], counting with OMSs, was also assessed as a NO-releasing materials due to the high biocompatibility of calcium cations. ${ }^{85}$ It showed a NO payload of $0.8 \mathrm{mmol} \cdot \mathrm{g}^{-1}$ and a sustained release during 10 hours under wet nitrogen gas. Recently, Serre and co-workers have proved the feasibility of coordinating NO to the OMSs of a titanium-based MOF, namely $\mathrm{Ti}_{12} \mathrm{O}_{15}$ (mdip) ${ }_{3}(\mathrm{OH})_{6}(\mathrm{H} 2 \mathrm{O})_{6}$ (mdip: 3,3',5,5'tetracarboxydiphenylmethane) by the in situ formation of complexed nitrites (Figure 6 b). ${ }^{86}$ ENREF 84 After a thermal treatment, bridged $\mathrm{Ti}-\mathrm{OH}-\mathrm{Ti}$ groups were generated in the secondary-building units, which after reacting with NO formed chemisorbed nitrites (NO payload of $1.3 \mathrm{mmol} \cdot \mathrm{g}^{-1}$ ). The material showed a slow NO release when suspended in PBS, not previously observed in NO-releasing MOFs due to the lability of the metal-NO bonds and/or the low stability of the frameworks in physiological media. In this case, given the high stability of the MOF, the sustained release was associated to the waterexchange of the chemisorbed nitrites. The material inhibited mitochondrial respiration in a concentration-dependent manner, demonstrating the control of the NO-releasing amount. The treatment of HeLa cells with the NO-releasing material favored the migration of the cells compared to the unloaded one, postulating its employment in wound-healing applications.

As mentioned above, all three gasotransmitters have lonepaired electrons. Therefore, it is possible to use OMSs in MOFs to store and deliver not only $\mathrm{NO}$ but also $\mathrm{CO}$ and $\mathrm{H}_{2} \mathrm{~S}$. N. Metzler-Nolte and co-workers used the MIL-88 (Fe) analogues for $\mathrm{CO}$ adsorption and release. ${ }^{87}$ In-situ ultrahigh vacuum-FTIR and Mössbauer spectroscopy studies of MIL-88B and MIL-88B$\mathrm{NH}_{2}$ confirmed the presence of $\mathrm{Fe}(\mathrm{II})-\mathrm{CO}$ and $\mathrm{Fe}(\mathrm{III})-\mathrm{CO}$ coordinations after the desorption cycle. In addition, the effect of the ligand functionality was also studied. It was found that the binding strength decreased in the case of MIL-88B- $\mathrm{NH}_{2}$ due to the electron donating effect of the amino group. CO releasing quantification was carried out through the myoglobin assay 
under physiological conditions in phosphate buffer at $\mathrm{pH}=$ 7.4. ${ }^{88}$ The CO release for bare MIL- $88 \mathrm{~B}$ and the amino functionalized version was $0.36 \mathrm{mmol} \cdot \mathrm{g}^{-1}$ and $0.69 \mathrm{mmol} \cdot \mathrm{g}^{-1}$ respectively. These values are consistent with the higher coordination strength in the $\mathrm{Fe}-\mathrm{CO}$ bond in the case of the unfunctionalized MIL-88B.

Morris and co-workers, further widen the scope of MOFs in the delivery of gasotransmitters by incorporating $\mathrm{H}_{2} \mathrm{~S}$ in the structure of CPO-27-M ( $\mathrm{M}=\mathrm{Ni}, \mathrm{Zn}) .{ }^{89}$ In close analogy to the case of $\mathrm{NO}, \mathrm{H}_{2} \mathrm{~S}$ was coordinated to the OMSs of both frameworks showing a maximum uptake close to $6.2 \mathrm{mmol} \cdot \mathrm{g}^{-1}$. The differences between the $\mathrm{Ni}$ and $\mathrm{Co}$ analogue appeared in their releasing performance. While the $\mathrm{H}_{2} \mathrm{~S}$ releasing capacity of CPO-27-Ni was $1.8 \mathrm{mmol} \cdot \mathrm{g}^{-1}$, in the case of CPO-27-Zn was 0.5 $\mathrm{mmol} \cdot \mathrm{g}^{-1}$. This difference is attributed to the difference in coordination strength between the OMSs and $\mathrm{H}_{2} \mathrm{~S}$. The capacity of $\mathrm{CPO}-27-\mathrm{Zn}$ to store $\mathrm{H}_{2} \mathrm{~S}$ and release it under physiological conditions enabled to test its vasodilation-induced properties in pre-contracted pig arteries. The immersion of the precontracted arteries in organ bath containing $\mathrm{H}_{2} \mathrm{~S}$-loaded CPO$27-\mathrm{Zn}$ resulted in an artery relaxation of $39 \%$.

\subsection{Catalysis}

OMSs located inside MOFs can be used as catalytic sites, which are easily accessible by the substrates owing to the intrinsic porosity of MOFs. Thanks to these complementary properties, MOFs have shown outstanding potential as catalysts. ${ }^{90}$ On the other hand, several catalytic mechanisms of NO releasing by decomposition of RSNO are widely known including coppermediated pathway. ${ }^{91}$

Reynolds and co-workers used the $\mathrm{Cu}$ (II) OMSs in the HKUST-1 structure to catalyze the decomposition reaction of a S-nitrosothiols (RSNO) into NO. Thus, HKUST-1 and Snitrosocysteine (CysNO) were suspended in an ethanolic solution and the NO generation was monitored. It was found that when the MOF was present the NO generation was sustained over the course of $12 \mathrm{~h}$. On the contrary, when only $\mathrm{Cu}(\mathrm{II})$ salts such as $\mathrm{CuCl}_{2}$ and $\mathrm{Cu}\left(\mathrm{CH}_{3} \mathrm{COO}\right)_{2}$ were employed only a burst release was found. These results suggest that the combination of OMSs and narrow pore architecture are responsible for the sustained NO release. ${ }^{92}$

A further step towards the integration of the catalytic NO releasing property into functional materials was provided by the same authors. To this end, HKUST-1 was immobilized in cotton fabrics to produce NO on surfaces. ${ }^{93}$ The composite material showed to be active in the catalytic decomposition of $S$ nitrosocysteamine (CysamNO) to produce NO. In fact, a NO release of $7.1 \mathrm{mmol} \cdot \mathrm{g}^{-1}$ was found over a period of $4 \mathrm{~h}$ in ethanol. However, as in earlier cases, the poor hydrolytic stability of HKUST-1 hindered its application in the biomedical field. In order to overcome this shortcoming, the water stable MOF $\left[\left(\mathrm{Cu}_{4} \mathrm{Cl}\right)_{3}(\mathrm{BTTri})_{8}\left(\mathrm{H}_{2} \mathrm{O}\right)_{12}\right] \cdot 72 \mathrm{H}_{2} \mathrm{O}$ (where BTTri is $1,3,5-$ tris(1H-1,2,3-triazol-5-yl)benzene) was synthesized and evaluated. The high chemical stability of the MOF allowed measuring its catalytic performance and NO release in PBS buffered solution. Thus, CuBTTri was able to release NO with the amount of $2.7 \mathrm{mmol} \cdot \mathrm{g}^{-1}$ in the course of 4 hours. The biomedical applicability of this MOF was further optimized by hybridizing it with biocompatible polymers such as polyurethane, poly(vinyl alcohol) and chitosan. Remarkably, the performance of the MOF was not diminished by its incorporation into polymeric supports, which enhances its practical implementation. ${ }^{94-96}$

\subsection{Encapsulation of gas-donor molecules}

The almost infinite possible combinations of metal ions/clusters and organic linkers to prepare metal-organic frameworks have resulted in a huge library of structures, some of them showing mesoporosity. Thanks to the larger size of the cavities, the framework can host bigger molecules than the gas itself (i.e. gas-donor molecules). The resulting gas-donor@MOF systems can modify the gas-release kinetics of the bare gasdonor (i.e. slowing down the gas release) and/or reduce the toxicity risks associated to the guest molecule by trapping it inside the pores and, therefore, limiting its leaching to the physiological media.

Barea et al. were pioneers in using the guest-encapsulation strategy to prepare a novel CO-releasing material based on a MOF. 50 The cationic photoCORM $\left[\mathrm{Mn}(\operatorname{tacn})(\mathrm{CO})_{3}\right] \mathrm{Br}$ (tacn = 1,4,7-triazacyclononane) was incorporated in the anionic metalorganic framework bio-MOF-1 $\left(\mathrm{NH}_{2}\left(\mathrm{CH}_{3}\right)_{2}\right)_{2}\left[\mathrm{Zn}_{8}\right.$ (adeninate) $4_{4}^{-}$ $\left.(\mathrm{BPDC})_{6}\right] \cdot 8 \mathrm{DMF} \cdot 11 \mathrm{H} 2 \mathrm{O}$ (BPDC $=4,4^{\prime}$-biphenyldicarboxylate) by means of a cationic exchange approach (Figure 7a). Although

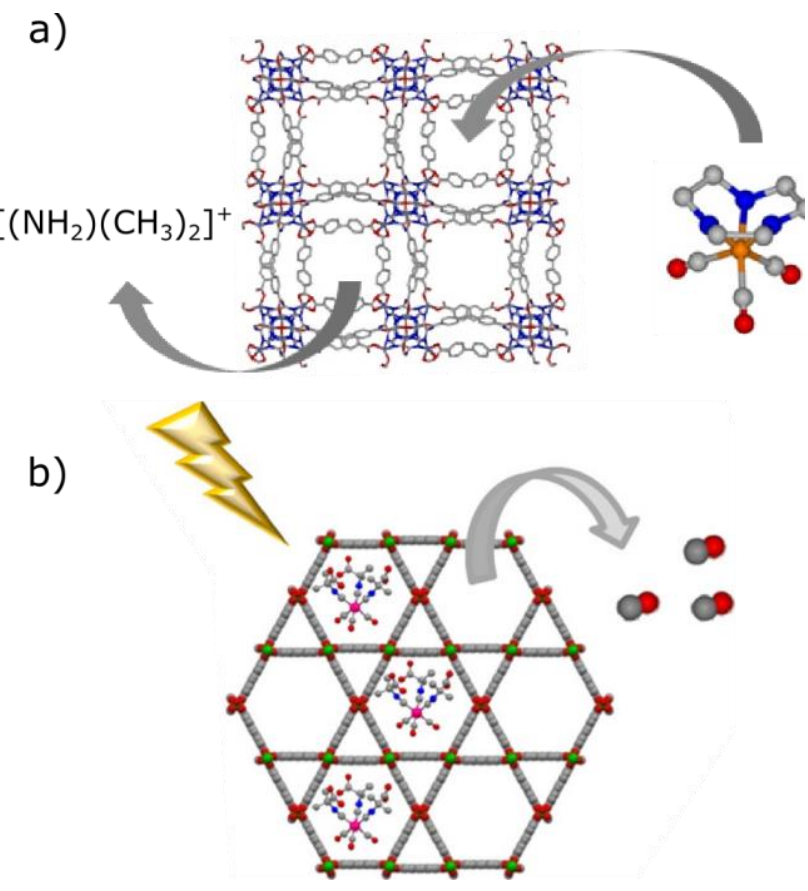

Figure 7: Schematic representations of the encapsulation of gas-donors into the cavities of metal-organic frameworks. a) Encapsulation of the photoCORM $\left[\mathrm{Mn}(\operatorname{tacn})(\mathrm{CO})_{3}\right] \mathrm{Br}$ into the porous framework bio-MOF-1 $\left.\left(\left(\mathrm{NH}_{2}\left(\mathrm{CH}_{3}\right)_{2}\right)_{2}[\mathrm{Zn} 8 \text { (adeninate })_{4}(\mathrm{BPDC})_{6}\right] \cdot 8 \mathrm{DMF} \cdot 11 \mathrm{H} 2 \mathrm{O}\right)$ by cationic exchange b) Representation of the light triggered $\mathrm{CO}$-release from the hybrid system photoCORM@MOF $\left[\mathrm{Mo}\left(\mathrm{CNCMe}_{2} \mathrm{CO}_{2} \mathrm{H}\right)_{3}(\mathrm{CO})_{3}\right] @[\mathrm{Al}(\mathrm{OH})($ stilbenedicarboxylate)]n. The MOF-based system releases $\mathrm{CO}$ under light irradiation while keeps trapped most of the metal-fragments encapsulated when suspended in physiological buffer. Adapted with permission from Ref. 98. Copyright 2018 American Chemical Society 
the material showed a high payload $(0.25 \mathrm{mmol}$ of CORM per gram of material), the scarce stability of the framework in physiological media led to almost full leaching of the CORM after 6 hours of incubation in PBS.

A CO-releasing material was prepared by the encapsulation of the photoCORM $\left[\mathrm{Mo}\left(\mathrm{CNCMe}_{2} \mathrm{CO}_{2} \mathrm{H}\right)_{3}(\mathrm{CO})_{3}\right]$ in a hierarchical structure of $\left[\mathrm{Zn}_{2}\right.$ (dobdc) $] \mathrm{n} .{ }^{97}$ The microporous nature of the $\mathrm{Zn}$ MOF with a pore aperture of $1.0 \times 1.4 \mathrm{~nm}$ may hamper the diffusion of the bulky Mo-CORM (ca. $1.3 \mathrm{~nm}$ ). To overcome these problems, the authors used a hierarchical structure of $\left[\mathrm{Zn}_{2}(\text { dobdc })\right]_{n}$ showing textural mesopores. The CORM was successfully encapsulated by one-pot synthesis-encapsulation ( $0.3 \mathrm{mmol}$ of CORM per gram of material). The hybrid system exhibited a more sustained CO-release than the pristine CORM when irradiated with UV light. In addition, the material was able to keep trapped the $87 \%$ of the Mo-fragment incorporated after incubation in physiological media, limiting its potential toxicity. The same CORM was also encapsulated in the cavities of the mesoporous MOF CYCU-3 $[\mathrm{Al}(\mathrm{OH})(\mathrm{SDC})]_{n},\left(\mathrm{H}_{2} \mathrm{SDC}\right.$ : 4,4stilbenedicarboxylic acid) (Figure 7b). ${ }^{98}$ The coordinationmodulation method ${ }^{99}$ was used to prepare several materials with different particle features, ranging from pseudosphericals nanoparticles to micrometric needles. Noteworthy, the use of higher concentration of modulator (50 times the linker concentration) led to a denser framework (CYCU-3'), whose structure was elucidated by continuous rotation electron diffraction (CRED). Although CYCU-3' showed a lower porosity than pristine CYCU-3, there channels were big enough to accommodate the CORM molecules, showing both systems similar payloads. Remarkably, the lower porosity in CYCU-3' resulted in higher stability, enabling to retain the $75 \%$ of Mofragments encapsulated after being suspended in PBS during 72 hours. In addition, the hybrid CYCU-3' system enabled a more sustained release of $\mathrm{CO}$, both in solution and solid state, increasing its potential toward different applications.

\subsection{Chemical attachment of gas-donors}

The versatility of MOFs enables to use functional ligands with ability to store and deliver gasotransmitters in their synthesis or incorporate them by post-synthetic modifications. This strategy offers the advantage of ensuring a very high payload of the donor moiety because it is incorporated in the structure. It also limits the extent of leaching, as in most of the cases the gas molecules are strongly attached to the organic moiety.

Diazeniumdiolate (NONOate) is probably the most famous NO-releasing functionality. It is easily synthesized from secondary amines under the high pressure of NO gas and release two molecules of NO by acid-catalyzed spontaneous decomposition with the first-order kinetics, thus the releasing rate of NO can be precisely predicted. Moreover, its decomposition rate can be tuned by subtle changes in its structure. ${ }^{100}$ Therefore, many kinds of NONOate derivatives, which have various half-lives ranging from few seconds to several hours, have been tested in experimental models of cardiovascular diseases.

Rosseinsky and co-workers were the first to synthesize the NONOate moiety inside a framework structure. ${ }^{101}$ In this study, a two-step post synthetic modification of HKUST-1 was implemented. First, 4-(methylamino)-pyridine (denote as 4map) was coordinated to the OMSs. Subsequently, the secondary amines were converted to NONOate functionality by reacting them with NO gas at high pressure. This second step was conditioned by the first step. The reaction did not occur when the loading of 4-map was close to $100 \%$ due to the pore blocking effect. On the other hand, the reaction proceeds when the loading was lower than $60 \%$. As a proof of concept, the NO delivery was confirmed in deionized water. However, the NO release was accompanied by significant 4-map leaching. Cohen and co-workers simplified the strategy by implementing it to two different MOFs, which contain the 2-aminoterephthalate moiety in their structure.102 Therefore, the NONOate functionality was introduced into $\left[\mathrm{Zn}_{4} \mathrm{O}\left(\mathrm{NH}_{2}-\mathrm{bdc}\right)\right]_{\mathrm{n}}$ (denote as IRMOF-3) ${ }^{103}$ and $\left[\mathrm{Zn}_{4} \mathrm{O}\left(\mathrm{NH}_{2} \text {-bdc) (btb }\right)_{4 / 3}\right]_{\mathrm{n}}$ (denote as UMCM-1$\mathrm{NH}_{2}$, btb = benzene-1,3,5-tribenzoate). ${ }^{104}$ The yield of the reaction (NONOate formation) for IRMOF-3 and UMCM-NH was $44 \%$ and $83 \%$ respectively, which is consistent with the higher porosity of the later. The releasing amount of NO in water was moderate in both cases (less than 10\%) due to the very rapid degradation of both structures.

The poor hydrolytic stability of the NONOate functionalized MOFs limits their scope as NO releasing vehicles in water (or physiological media). However, they can be employed in the sustained release of $\mathrm{NO}$ in solid state upon exposure to humid gas. To this end, a ligand bearing three amine functionalities was employed in the synthesis of the MOF $\left[\mathrm{Cu}_{3}(\text { TDPAT })\left(\mathrm{H}_{2} \mathrm{O}\right)_{3}\right]_{\mathrm{n}}$ framework (denote as Cu-TDPAT, TDPAT $=2,4,6$-tris $(3,5$ dicarboxylphenylamino)-1,3,5-triazine). ${ }^{105}$ The amine functionalities were converted to NONOate functionalities by reaction with $\mathrm{NO}$ gas, likewise previously introduced IRMOF-3 and UMCM-1-NH $\mathrm{NH}_{2}$. The NO releasing experiments in the solid state revealed that the CU-TDPAT NONOate released NO when contacted to humid gas ( $\mathrm{RH}=85 \%$ ) over the course of 7 days and with a maximum release of $0.175 \mathrm{mmol} \cdot \mathrm{g}^{-1}$.

Most of the NO-releasing MOFs discussed so far used humidity (water molecule) to trigger the release. However, humidity is a not an easy to control parameter in real physiological conditions, which implies that the degree of control in the delivery of the bio gas is limited. On the other hand, light is a more suitable stimulus because it is non-invasive and can be manipulated in terms of intensity, wavelength and location. Therefore, the use of photodonor ligands as part of the framework is a promising strategy to develop new photoresponsive gasotransmitters releasing materials. Furukawa, Kamei and co-workers first implemented this strategy by using imidazole ligands bearing the nitro functionality in the synthesis of zeolitic imidazole frameworks (ZIF) (Figure 8a). Aromatic molecules with nitro groups are well known for their NO photogeneration. ${ }^{106,107}$ Thus, the reaction of 2-nitroimidazole (2-nIm) or 5-methyl-4-nitroimidazole $(\mathrm{mnlm})$ with $\mathrm{Zn}(\mathrm{II})$ ions yielded $\left[\mathrm{Zn}(2 \mathrm{nIm})_{2}\right]_{\mathrm{n}}$ (NOF-1) and $\left[\mathrm{Zn}(\mathrm{mnlm})_{2}\right]_{\mathrm{n}} \quad(\mathrm{NOF}-2) .{ }^{108}$ Interestingly, both frameworks showed light triggered NO release in the solid-state with a maximum release of $3 \mathrm{mmol} \cdot \mathrm{g}^{-1}$. The light used for these experiments was set at $365 \mathrm{~nm}$. Interestingly, The NO release 
duration and rate could be controlled by light on/off and intensity. It is noteworthy that the light triggered NO releasing efficiency of the ligands themselves was significantly lower (less than $0.5 \mathrm{mmol} \cdot \mathrm{g}^{-1}$ ) than the respective frameworks. The difference in photoreactivity between the frameworks and the ligands is attributed to the structuring effect of the frameworks. The spatial segregation of the photoreactive moieties within the framework avoids the aggregation induced quenching observed in the ligands in the solid-state, which paves the way to new solid-state NO releasing materials. The solid-state delivery of NO of NOF-1 crystals enabled to integrate them into substrates that can then be used as functional extracellular scaffolds. Using this cell culture platform, the spatiotemporal stimulation of cells by NO was demonstrated, which subsequently caused an increase of intracellular $\mathrm{Ca}^{2+}$ ion concentration in the genetically modified HEK293 cells with TRPC5 channels.

Besides the nitro aromatic groups, the bis-N-nitroso (BNN) moiety is also known to release NO upon light irradiation. However, its low thermal stability prevents to use it in the direct synthesis of the MOF. Thus, it must be incorporated in the framework structure by post-synthetic modification through nitrosation of secondary amines. Therefore, two MOFs with bisamino moieties in their structure were synthesized; $\left[\mathrm{Ti}_{8} \mathrm{O}_{8}(\mathrm{OH})_{4}(\mathrm{MeNH}-\mathrm{bdc})_{6}\right]_{\mathrm{n}}$ (preNOF-11) and the $\left[\mathrm{Al}_{8}(\mathrm{OMe})_{8}(\mathrm{OH})_{4}(\mathrm{MeNH}-\mathrm{bdc})_{6}\right]_{\mathrm{n}}$ (preNOF-12), where MeNH-bdc is 2,5-bis(methylamino)-1,4-benzenedicarboxylic acid. Subsequently, the BNN moiety was introduced by postsynthetic nitrosation. ${ }^{109}$ NOF-11 and NOF-12 released 1.60 $\mathrm{mmol} \cdot \mathrm{g}^{-1}$ and $2.78 \mathrm{mmol} \cdot \mathrm{g}^{-1}$, respectively, upon white light $(300-600 \mathrm{~nm})$ irradiation in the solid-state. Contrariwise to the above-mentioned examples, both frameworks showed a remarkable stability not only in water but also in phosphate

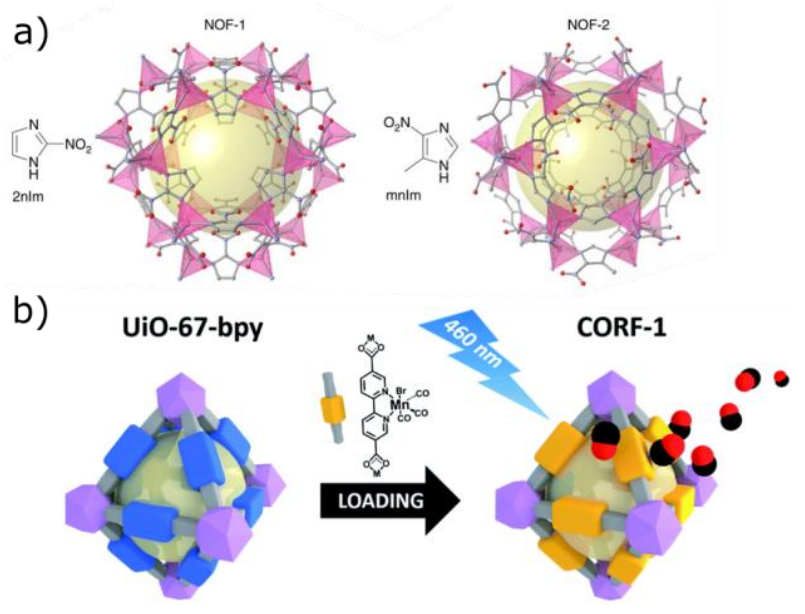

Figure 8: Examples of photoresponsive gas-releasing metal-organic frameworks prepared by the chemical attachment of gas donors. a) Chemical structures of $\left[\mathrm{Zn}\left(2 \mathrm{n} / \mathrm{m}_{2}\right]_{\mathrm{n}}\right.$ (NOF-1) and $\left[\mathrm{Zn}(\mathrm{mnlm})_{2}\right]_{\mathrm{n}}$ (NOF-2). Reprinted with permission from Ref. 108 , b) Post-functionalization of the linker of the MOF $\left[\mathrm{Zr}_{6} \mathrm{O}_{4}(\mathrm{OH})_{4}(\mathrm{bpydc})_{6}\right]$ with a manganese-carbonyl group to generate a photoresponsive CO-releasing material. Reprinted from Ref. 113 with permission from the Royal Society of Chemistry.

buffered solutions. This high stability stems from two facts; the strong coordination of high valence metal ions, such as Ti(IV) and $\mathrm{Al}(\mathrm{III})$ with carboxylates, ${ }^{110}$ and the BNN moiety decorating the pores, which hinders water and phosphate inclusion preventing hydrolytic degradation.

Even though the most common strategy consists in introducing in the MOF synthesis ligands with the potential to release gasotransmitter molecules under certain stimuli, behaving as pro-drugs, it is also possible to exploit the affinity of these gases towards certain organic groups. This was recently demonstrated by Alkordi and co-workers. They showed that the $\mathrm{NH}_{2}$ functionality decorating the pores of the UiO-66- $\mathrm{NH}_{2}$ can trap up to $6.2 \mathrm{mmol} \cdot \mathrm{g}^{-1}$ by chemisorption. The loaded compound released up to $1.1 \mathrm{mmol} \cdot \mathrm{g}^{-1}$ in acidified PBS media. ${ }^{111}$

The presence of free moieties with coordination capabilities decorating the pores of the MOF can be exploited to incorporate metal complexes to the structure through post synthetic modifications. A paradigmatic example of this approach is provided by the reactivity of ligands bearing free 2,2-bipyridine moieties towards transition metal ions. ${ }^{112}$ This reactivity was exploited to incorporate the $\mathrm{CO}$ photoreleasing moiety $\mathrm{MnBr}$ (bpydc)(CO) 3 (bpydc is 5,5-dicarboxylate-2,2bipyridine) within the porous structure of the $\mathrm{Zr}$ (IV) based UiO$67\left[\mathrm{Zr}_{6} \mathrm{O}_{4}(\mathrm{OH})_{4}(\mathrm{bpydc})_{6}\right]$ through post synthetic metalation of the free 2,2-bipyridine centers with $\operatorname{MnBr}(\mathrm{CO})_{5}$ (Figure 8b). ${ }^{113}$ The $\mathrm{MnBr}$ (bpydc)(CO) ${ }_{3} @ U i \mathrm{O}-67$ (named as CORF-1) was able to efficiently release $\mathrm{CO}$ in the solid-state upon visible light irradiation $\left(465 \mathrm{~nm}\right.$ ) with a maximum release of $4.7 \mathrm{mmol} \cdot \mathrm{g}^{-1}$, which was easily controlled by turning on and off the light source. These features enabled to prepare photoresponsive CO releasing cell-growth substrates by immobilizing CORF-1 crystals within the biocompatible PDMS polymer. These functional cellular scaffolds were used to observe the cellular uptake of the on-demand generated CO from the CORF-1 crystals.

\section{Protein assemblies}

Protein crystals, which are the solid-state assembly of proteins, engaged interest as porous materials. Typical protein crystals show from 30 to $65 \%$ of void volume that are filled by solvent molecules. ${ }^{114}$ The pore surface is composed of residual amino acid chains, which have a potential as metal coordination site and, therefore, can be used for anchoring gas-donor to the biomaterial. ${ }^{115,} 116$ The low yield in the synthesis of protein crystals and their low stability are the main disadvantages of this strategy. On the other hand, their inherent lack of toxicity is a great advantage. In fact, protein assemblies are the more biocompatible gasotransmitter carriers discussed in this review.

\subsection{Chemical functionalization with gas-donor}

Romao and co-workers studied, for the first time, the interaction of CO-releasing molecules, namely [fac$\mathrm{Ru}(\mathrm{CO})_{3} \mathrm{Cl}$ (glycinate)], (CORM-3), and different proteins. They observed the coordination of the carbonyl-metal to side chains of amino acids, forming $\mathrm{Ru}(\mathrm{CO})_{2}$-proteins adducts with the concomitant loss of one $\mathrm{CO}$ and glycinate ligands. However, 


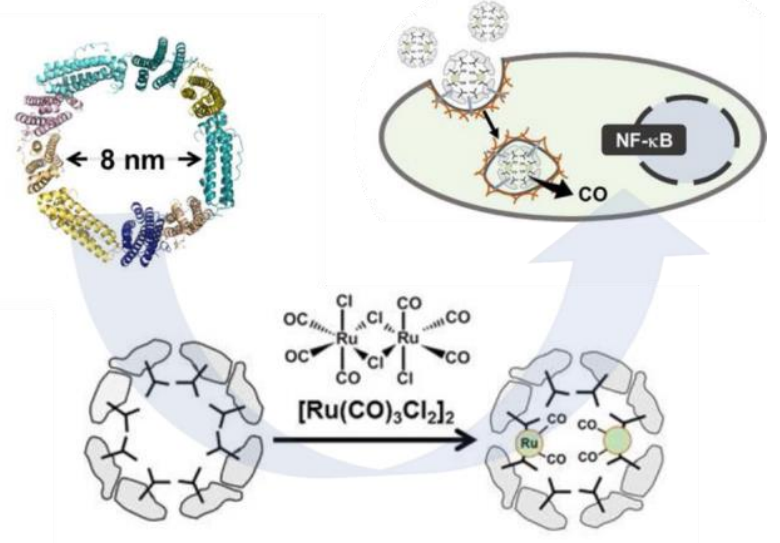

Figure 9: Schematic representation of subunit of ferritin with an inner diameter of $8 \mathrm{~nm}$ ), formation of $\mathrm{Ru}(\mathrm{CO})_{2}$-protein adduct and cellular uptake of Ferritin$\mathrm{Ru}(\mathrm{CO})_{2}$ composite and intracellular CO-release. Adapted with permission from reference 119. Copyright 2014 American Chemical Society.

they did not study the potential CO-releasing properties of these new materials. ${ }^{117,} 118$ Later, Ueno and co-workers proved the feasibility of using ferritin as a CO-donor carrier. ${ }^{119}$ This protein includes 24 subunits with $8 \mathrm{~nm}$ or inner diameter (Figure 9). By reacting with $\left[\mathrm{Ru}(\mathrm{CO})_{3} \mathrm{Cl}_{2}\right]_{2}$, protein- $\mathrm{Ru}(\mathrm{CO})_{2}$ were formed. With the aim to modulate the CO-releasing properties of the system, they used three different ferritin mutants, counting with a distinct proportion of side chain aminoamides, resulting in 3 novel CO-releasing materials. All composites slowed down the CO-release rate in comparison to the pristine CORM when suspended in physiological conditions. In addition, the cellular uptake of the composites was superior to the bare CORM, proving the utility of protein cages as a carrier of COreleasing molecules. In another work, they extended this approach to attach ruthenium carbonyls to a cross-linked hen egg with lysozyme crystals. As in the case of the ferritin, the novel nanocomposites showed a slower CO-release than the pristine CORM when suspended in physiological media. Furthermore, they elicited biological response when incubated in living cells. ${ }^{120}$ The same authors further gained control on the delivery of $\mathrm{CO}$ from protein assemblies by introducing a $\mathrm{Mn}(\mathrm{I})$ based photoCORM. ${ }^{121}$ Thus, a mutant version of ferritin rich in cysteines was used to coordinate $\mathrm{Mn}(\mathrm{l})$ carbonyl species. Interestingly the composite protein assembly only release $\mathrm{CO}$ upon light irradiation at $456 \mathrm{~nm}$. Thanks to the biocompatible nature of the $\mathrm{CO}$ carrier, it could be used as an intracellular $\mathrm{CO}$ delivery vehicle. The high degree of control achieved in the $\mathrm{CO}$ delivery together with the biocompatibility of the carrier makes this material highly promising to further understand the role of $\mathrm{CO}$ at cellular level.

\section{Conclusions and outlook}

After nearly fifteen years of a multidisciplinary research that combined gas biology and porous materials, the resulting knowledge has led to a versatile toolbox of materials and strategies to load and release gasotransmitters from porous materials. Thus, researchers can tune the stimuli to deliver gases from porous materials as well as to control its release kinetics to meet the criteria for selected biomedical applications, such as wound healing, vasodilation and antiinflammation among others.

As we have summarized in the review, zeolites offer a robust and non-toxic framework with well-ordered OMS being able to store NO that can be spontaneously released through water exchange or produce it in situ through catalytic reactions. Therefore, while zeolites excel in the prolonged and spontaneous release of $\mathrm{NO}$, it is challenging to modulate their performance toward NO release on demand because humidity and concentration of reactants cannot be easily modulated in vivo. Alternatively, the large pores of mesoporous silica allow encapsulating gas releasing molecules that are sensitive to different stimuli such as light and heat. This strategy offers the advantage of easily incorporating the advances achieved in the field of gasotransmitter-releasing molecules into the porous material field. Thus, mesoporous silica have proven to be versatile materials for releasing all known gasotransmitters through different stimuli, which made it possible to attain important goals in the field of gas biology such as on-demand gasotransmitter release. MOFs provided their versatility in terms of structures, composition and reactivity to the field of gas biology, which enabled the development of novel routes toward the controlled release of gasotransmitters. For example, the incorporation of gas releasing moieties in the organic linker of the MOF did not only achieve high payloads of gases but also their light triggered release in the solid-state paving the way for its implementation in novel devices. All these materials share the fact that they are exogenous, which might rise some concerns on their biocompatibility. In this regard, protein assemblies offer inherently biocompatible scaffolds where to localize gasotransmitters at the cost of providing low payloads and stability.

However, as highlighted in several examples across this review, the successful implementation of porous materials for the therapeutic release of gasotransmitters in the real world application requires an appropriate strategy for their materialization/formulation and administration. Thus, processing of gasotransmitter releasing porous materials into stable colloids, gels, ointments or shape them into macroscopic object through hybridization with other materials such as polymers is a promising strategy toward their practical use. All these strategies entail specific challenges that still need to be overcome. For instance, the intravenous administration of the porous carriers implies the use of nanoscopic carriers with narrow size distribution and structural and colloidal stability in physiological media. In this regard, coating the porous carriers with biocompatible polymers and lipids have shown to be a promising strategy to prevent degradation and increase colloidal stability. Alternatively, the use of non-toxic building blocks held by strong interactions in the synthesis of nanoscopic porous carriers has shown to increase the stability/biocompatibility of the porous carrier as exemplified by titanosilicates and MOFs made with high valence metal ions (i. e. Fe(III), $\mathrm{Zr}(\mathrm{IV})$ and Ti(IV)). The synthesis of stable nano-sized 
porous carriers for gasotransmitters together with further studies on their biodistribution will pave the way for their efficient intravenous administration. On the other hand, the use of macroscopic devices to exogenously deliver gasotransmitters to targeted organs must ensure a robust and reproducible performance over several cycles. In this regard, the possibility to shape porous materials into gels, ${ }^{122}$ liquids, ${ }^{123}$ melted liquids ${ }^{124}$ or monoliths ${ }^{125}$ seem a promising strategy to process these materials into macroscopic objects without the need of an external matrix that dilute them.

\section{Conflicts of interest}

There are no conflicts to declare.

\section{Acknowledgements}

The authors acknowledge iCeMS for supporting the gas biology materials project. This research was supported by AMED under Grant Number 20lm0203013j0002.

\section{Notes and references}

1. A. K. Mustafa, M. M. Gadalla, N. Sen, S. Kim, W. Mu, S. K. Gazi, R. K. Barrow, G. Yang, R. Wang and S. H. Snyder, Sci. Signal, 2009, 2, ra72-ra72.

2.

R. Wang, Trends Biochem. Sci, 2014, 39, 227-232.

R. M. J. Palmer, A. G. Ferrige and S. Moncada, Nature, 1987, 327, 524.

D. J. Stuehr, Biochim. Biophys. Acta Bioenerg., 1999, 1411, $217-$ 230.

R. Tenhunen, H. S. Marver and R. Schmid, Proc. Natl. Acad. Sci. U. S. A., 1968, 61, 748-755.

L. Wu and R. Wang, Pharmacol. Rev., 2005, 57, 585-630.

R. Motterlini and L. E. Otterbein, Nat. Rev. Drug Discov., 2010, 9 , 728-743.

M. S. Vandiver and S. H. Snyder, J. Mol. Med. (Berl.), 2012, 90, 255-263.

R. Wang, Physiol. Rev., 2012, 92, 791-896.

D. Babu, R. Motterlini and R. A. Lefebvre, Br. J. Pharmacol., 2015, 172, 1557-1573.

C. C. Romão, W. A. Blättler, J. D. Seixas and G. J. L. Bernardes, Chem. Soc. Rev., 2012, 41, 3571-3583.

U. Schatzschneider, Br. J. Pharmacol., 2015, 172, 1638-1650.

P. G. Wang, M. Xian, X. Tang, X. Wu, Z. Wen, T. Cai and A. J. Janczuk, Chem. Rev., 2002, 102, 1091-1134.

N. Naghavi, A. de Mel, O. S. Alavijeh, B. G. Cousins and A. M. Seifalian, Small, 2013, 9, 22-35.

Y. Zhao, T. D. Biggs and M. Xian, Chem. Commun., 2014, 50, 11788-11805.

S. M. Fix, M. A. Borden and P. A. Dayton, J. Control. Release, 2015, 209, 139-149.

T. Yang, A. N. Zelikin and R. Chandrawati, Adv. Sci., 2018, 5, 1701043.

K. Ling, F. Men, W.-C. Wang, Y.-Q. Zhou, H.-W. Zhang and D.W. Ye, J. Med. Chem., 2018, 61, 2611-2635.

M. E. Davis, Nature, 2002, 417, 813 .

S. Wang, Microporous Mesoporous Mater., 2009, 117, 1-9.

K. Hadjiivanov, E. Ivanova and H. Knözinger, Microporous Mesoporous Mater., 2003, 58, 225-236.

M. Ozekmekci, G. Salkic and M. F. Fellah, Fuel Process. Technol., 2015, 139, 49-60.
P. S. Wheatley, A. R. Butler, M. S. Crane, S. Fox, B. Xiao, A. G. Rossi, I. L. Megson and R. E. Morris, J. Am. Chem. Soc., 2006, 128, 502-509.

H. A. Liu and K. J. Balkus, Chem. Mater., 2009, 21, 5032-5041.

S. Fox, T. S. Wilkinson, P. S. Wheatley, B. Xiao, R. E. Morris, A. Sutherland, A. J. Simpson, P. G. Barlow, A. R. Butler, I. L. Megson and A. G. Rossi, Acta Biomater., 2010, 6, 1515-1521.

M. Neidrauer, U. K. Ercan, A. Bhattacharyya, J. Samuels, J. Sedlak, R. Trikha, K. A. Barbee, M. S. Weingarten and S. G. Joshi, J. Med. Microbiol., 2014, 63, 203-209.

M. L. Pinto, J. Rocha, J. R. B. Gomes and J. Pires, J. Am. Chem. Soc., 2011, 133, 6396-6402.

M. L. Pinto, A. C. Fernandes, J. Rocha, A. Ferreira, F. Antunes and J. Pires, J. Mat. Chem. B, 2014, 2, 224-230.

M. L. Pinto, A. C. Fernandes, F. Antunes, J. Pires and J. Rocha, Microporous Mesoporous Mater., 2016, 229, 83-89.

R. V. Pinto, A. C. Fernandes, F. Antunes, Z. Lin, J. Rocha, J. Pires and M. L. Pinto, Nitric Oxide, 2019, 90, 29-36.

E. I. Tocheva, F. I. Rosell, A. G. Mauk and M. E. P. Murphy, Science, 2004, 304, 867.

A.-K. Boes, P. S. Wheatley, B. Xiao, I. L. Megson and R. E. Morris, Chem. Commun., 2008, 6146-6148.

G. Turnes Palomino, P. Fisicaro, S. Bordiga, A. Zecchina, E Giamello and C. Lamberti, J. Phys. Chem. B, 2000, 104, 40644073.

W. J. Roth, P. Nachtigall, R. E. Morris, P. S. Wheatley, V. R. Seymour, S. E. Ashbrook, P. Chlubná, L. Grajciar, M. Položij, A. Zukal, O. Shvets and J. Čejka, Nat. Chem., 2013, 5, 628-633.

R. A. Doyle, S. E. Russell and R. E. Morris, Microporous Mesoporous Mater., 2019, 280, 367-371.

S. E. Russell, J. M. González Carballo, C. Orellana-Tavra, D. Fairen-Jimenez and R. E. Morris, Dalton. Trans., 2017, 46, 39153920.

J. L. Vivero-Escoto, I. I. Slowing, B. G. Trewyn and V. S. Y. Lin, Small, 2010, 6, 1952-1967.

Z. Li, J. C. Barnes, A. Bosoy, J. F. Stoddart and J. I. Zink, Chem. Soc. Rev., 2012, 41, 2590-2605.

40. F. Hoffmann, M. Cornelius, J. Morell and M. Fröba, Angew. Chem. Int. Ed., 2006, 45, 3216-3251.

J. J. Koehler, J. Zhao, S. S. Jedlicka, D. M. Porterfield and J. L. Rickus, J. Phys. Chem. B, 2008, 112, 15086-15093.

V. P. Torchilin, Adv. Drug Deliv. Rev., 2006, 58, 1532-1555.

42. D. Peer, J. M. Karp, S. Hong, O. C. Farokhzad, R. Margalit and R. Langer, Nat. Nanotechnol., 2007, 2, 751.

D. M. Porterfield, J. D. Laskin, S.-K. Jung, R. P. Malchow, B. Billack, P. J. S. Smith and D. E. Heck, Am. J. Physiol. Lung Cell Mol. Physiol., 2001, 281, L904-L912.

45. C. Zolkov, D. Avnir and R. Armon, J. Mater. Chem., 2004, 14, 2200-2205.

S. S. Jedlicka, J. L. McKenzie, S. J. Leavesley, K. M. Little, T. J. Webster, J. P. Robinson, D. E. Nivens and J. L. Rickus, J. Mater. Chem., 2006, 16, 3221-3230.

$47 . \quad$ B. J. Heilman, J. St. John, S. R. J. Oliver and P. K. Mascharak, J. Am. Chem. Soc., 2012, 134, 11573-11582.

X. Zhang, G. Tian, W. Yin, L. Wang, X. Zheng, L. Yan, J. Li, H. Su, C. Chen, Z. Gu and Y. Zhao, Adv. Funct. Mater., 2015, 25, 3049-3056.

49. C. Hu, J. Sun, Y. Zhang, J. Chen, Y. Lei, X. Sun and Y. Deng, Adv Healthc. Mater., 2018, 7, 1801047.

50. F. J. Carmona, S. Rojas, P. Sánchez, H. Jeremias, A. R. Marques, C. C. Romão, D. Choquesillo-Lazarte, J. A. R. Navarro, C. R. Maldonado and E. Barea, Inorg. Chem., 2016, 55, 6525-6531.

M. A. Gonzales, H. Han, A. Moyes, A. Radinos, A. J. Hobbs, N. Coombs, S. R. J. Oliver and P. K. Mascharak, J. Mat. Chem. B, 2014, 2, 2107-2113.

52. I. Chakraborty, S. J. Carrington, J. Hauser, S. R. J. Oliver and P. K. Mascharak, Chem. Mater., 2015, 27, 8387-8397.

53. F. J. Carmona, I. Jiménez-Amezcua, S. Rojas, C. C. Romão, J. A R. Navarro, C. R. Maldonado and E. Barea, Inorg. Chem., 2017, 56, 10474-10480.

54. G. Caliendo, G. Cirino, V. Santagada and J. L. Wallace, J. Med. Chem., 2010, 53, 6275-6286. 

K. Zhu, Y. Liu, W. Yang, C. Guo, D. Zhao and C. Wang, J. Mat. Chem. B, 2015, 3, 4451-4457. W. Wang, X. Sun, H. Zhang, C. Yang, Y. Liu, W. Yang, C. Guo and C. Wang, Int. J. Nanomedicine, 2016, 11, 3255-3263. S. M. C. Neiva, J. A. V. Santos, J. C. Moreira, Y. Gushikem, H. Vargas and D. W. Franco, Langmuir, 1993, 9, 2982-2985.

B. J. Nablo, T.-Y. Chen and M. H. Schoenfisch, J. Am. Chem. Soc., 2001, 123, 9712-9713. 2006, 22, 203-208

60. F. G. Doro, U. P. Rodrigues-Filho and E. Tfouni, J. Colloid, Interf Sci., 2007, 307, 405-417.

61. J. H. Shin, S. K. Metzger and M. H. Schoenfisch, J. Am. Chem. Soc., 2007, 129, 4612-4619.

F. O. N. da Silva, E. C. C. Gomes, T. d. S. Francisco, A. K. M Holanda, I. C. N. Diógenes, E. H. S. de Sousa, L. G. F. Lopes and E. Longhinotti, Polyhedron, 2010, 29, 3349-3354. F. Wei, Q. Hou, J. Y. Yang and J. H. Zhu, J. Colloid, Interf. Sci., 2011, 356, 526-535.

64. M. B. Yue, L. B. Sun, T. T. Zhuang, X. Dong, Y. Chun and J. H. Zhu, J. Mater. Chem., 2008, 18, 2044-2050.

R. J. Soto, L. Yang and M. H. Schoenfisch, ACS Appl. Mater. Int 2016, 8, 2220-2231.

66. A. L. Tessaro, A. Fraix, A. C. Pedrozo da Silva, E. Gazzano, C. Riganti and S. Sortino, Nanomaterials, 2019, 9, 823.

67. D. Afonso, S. Valetti, A. Fraix, C. Bascetta, S. Petralia, S. Conoci, A. Feiler and S. Sortino, Nanoscale, 2017, 9, 13404-13408.

68. M. J. Malone-Povolny and M. H. Schoenfisch, ACS Appl. Mater Int., 2019, 11, 12216-12223.

69. R. Guo, Y. Tian, Y. Wang and W. Yang, Adv. Funct. Mater., 2017, 27, 1606398

O. M. Yaghi, M. O'Keeffe, N. W. Ockwig, H. K. Chae, M Eddaoudi and J. Kim, Nature, 2003, 423, 705

71. S. Kitagawa, R. Kitaura and S.-i. Noro, Angew. Chem. Int. Ed., 2004, 43, 2334-2375.

72. G. Férey, C. Mellot-Draznieks, C. Serre and F. Millange, Acc. Chem. Res., 2005, 38, 217-225.

73. P. Horcajada, R. Gref, T. Baati, P. K. Allan, G. Maurin, P Couvreur, G. Férey, R. E. Morris and C. Serre, Chem. Rev., 2012, 112, 1232-1268

74. X. Kong, E. Scott, W. Ding, J. A. Mason, J. R. Long and J. A. Reimer, J. Am. Chem. Soc., 2012, 134, 14341-14344. B. Xiao, P. S. Wheatley, X. Zhao, A. J. Fletcher, S. Fox, A. G. Rossi, I. L. Megson, S. Bordiga, L. Regli, K. M. Thomas and R. E. Morris, J. Am. Chem. Soc., 2007, 129, 1203-1209. C. McKinlay, B. Xiao, D. S. Wragg, P. S. Wheatley, I. L. Megson and R. E. Morris, J. Am. Chem. Soc., 2008, 130, 10440 10444

77. F. Bonino, S. Chavan, J. G. Vitillo, E. Groppo, G. Agostini, C. Lamberti, P. D. C. Dietzel, C. Prestipino and S. Bordiga, Chem. Mater., 2008, 20, 4957-4968.

78 D. Cattaneo, S. J. Warrender, M. J. Duncan, C. J. Kelsall, M. K. Doherty, P. D. Whitfield, I. L. Megson and R. E. Morris, RSC Adv., 2016, 6, 14059-14067.

E. D. Bloch, W. L. Queen, S. Chavan, P. S. Wheatley, J. M Zadrozny, R. Morris, C. M. Brown, C. Lamberti, S. Bordiga and J. R. Long, J. Am. Chem. Soc., 2015, 137, 3466-3469. S. Rojas, P. S. Wheatley, E. Quartapelle-Procopio, B. Gil, B. Marszalek, R. E. Morris and E. Barea, CrystEngComm, 2013, 15, 9364-9367.

81. À. Ruyra, A. Yazdi, J. Espín, A. Carné-Sánchez, N. Roher, J. Lorenzo, I. Imaz and D. Maspoch, Chem. Eur. J., 2015, 21, 25082518.

82. P. Horcajada, T. Chalati, C. Serre, B. Gillet, C. Sebrie, T. Baati, J F. Eubank, D. Heurtaux, P. Clayette, C. Kreuz, J.-S. Chang, Y. K. Hwang, V. Marsaud, P.-N. Bories, L. Cynober, S. Gil, G. Férey, P. Couvreur and R. Gref, Nat. Mater., 2009, 9, 172 P. Bazin, J. C. Lavalley, M. Daturi, A. Vimont, G. De Weireld, P. Horcajada, C. Serre and R. E. Morris, Chem. Mater., 2013, 25, 1592-1599.

84.

85.

86.

87.

88.

91

92.

93.

94.

95.

96.

97.

98.

100

101.

102.

103.

104.

105.

106.

107.

108.

109.

110.

111.

113.

114.

115.

116.
J. F. Eubank, P. S. Wheatley, G. Lebars, A. C. McKinlay, H. Leclerc, P. Horcajada, M. Daturi, A. Vimont, R. E. Morris and C. Serre, APL Mater., 2014, 2, 124112

S. R. Miller, E. Alvarez, L. Fradcourt, T. Devic, S. Wuttke, P. S. Wheatley, N. Steunou, C. Bonhomme, C. Gervais, D. Laurencin, R. E. Morris, A. Vimont, M. Daturi, P. Horcajada and C. Serre, Chem. Commun., 2013, 49, 7773-7775.

R. V. Pinto, S. Wang, S. R. Tavares, J. Pires, F. Antunes, A. Vimont, G. Clet, M. Daturi, G. Maurin, C. Serre and M. L. Pinto, Angew. Chem. Int. Ed., 2020, 59, 5135-5143.

M. Ma, H. Noei, B. Mienert, J. Niesel, E. Bill, M. Muhler, R. A. Fischer, Y. Wang, U. Schatzschneider and N. Metzler-Nolte, Chem. Eur. J., 2013, 19, 6785-6790.

A. J. Atkin, J. M. Lynam, B. E. Moulton, P. Sawle, R. Motterlini, N. M. Boyle, M. T. Pryce and I. J. S. Fairlamb, Dalton. Trans., 2011, 40, 5755-5761.

P. K. Allan, P. S. Wheatley, D. Aldous, M. I. Mohideen, C. Tang, J. A. Hriljac, I. L. Megson, K. W. Chapman, G. De Weireld, S. Vaesen and R. E. Morris, Dalton. Trans., 2012, 41, 4060-4066.

J. Lee, O. K. Farha, J. Roberts, K. A. Scheidt, S. T. Nguyen and J. T. Hupp, Chem. Soc. Rev., 2009, 38, 1450-1459.

D. L. H. Williams, Acc. Chem. Res., 1999, 32, 869-876.

J. L. Harding and M. M. Reynolds, J. Am. Chem. Soc., 2012, 134 3330-3333.

M. J. Neufeld, J. L. Harding and M. M. Reynolds, ACS Appl. Mater. Int., 2015, 7, 26742-26750.

J. L. Harding, J. M. Metz and M. M. Reynolds, Adv. Funct. Mater., 2014, 24, 7503-7509.

M. J. Neufeld, A. Lutzke, J. B. Tapia and M. M. Reynolds, ACS Appl. Mater. Int., 2017, 9, 5139-5148.

M. J. Neufeld, A. Lutzke, W. M. Jones and M. M. Reynolds, ACS Appl. Mater. Int., 2017, 9, 35628-35641.

F. J. Carmona, S. Rojas, C. C. Romão, J. A. R. Navarro, E. Barea and C. R. Maldonado, Chem. Commun., 2017, 53, 6581-6584.

F. J. Carmona, C. R. Maldonado, S. Ikemura, C. C. Romão, Z. Huang, H. Xu, X. Zou, S. Kitagawa, S. Furukawa and E. Barea, ACS Appl. Mater. Int., 2018, 10, 31158-31167.

T. Tsuruoka, S. Furukawa, Y. Takashima, K. Yoshida, S. Isoda and S. Kitagawa, Angew. Chem. Int. Ed., 2009, 48, 4739-4743.

J. A. Hrabie, J. R. Klose, D. A. Wink and L. K. Keefer, J. Org. Chem., 1993, 58, 1472-1476.

M. J. Ingleson, R. Heck, J. A. Gould and M. J. Rosseinsky, Inorg. Chem., 2009, 48, 9986-9988.

J. G. Nguyen, K. K. Tanabe and S. M. Cohen, CrystEngComm, 2010, 12, 2335-2338.

M. Eddaoudi, J. Kim, N. Rosi, D. Vodak, J. Wachter, M. O'Keeffe and O. M. Yaghi, Science, 2002, 295, 469-472.

Z. Wang, K. K. Tanabe and S. M. Cohen, Inorg. Chem., 2009, 48, 296-306.

A. Lowe, P. Chittajallu, Q. Gong, J. Li and K. J. Balkus, Microporous Mesoporous Mater., 2013, 181, 17-22.

K. Hishikawa, H. Nakagawa, T. Furuta, K. Fukuhara, H. Tsumoto, T. Suzuki and N. Miyata, J. Am. Chem. Soc., 2009, 131, 7488-7489. S. Sortino, Chem. Soc. Rev., 2010, 39, 2903-2913.

S. Diring, D. O. Wang, C. Kim, M. Kondo, Y. Chen, S. Kitagawa, K.-i. Kamei and S. Furukawa, Nat. Commun., 2013, 4, 2684.

C. Kim, S. Diring, S. Furukawa and S. Kitagawa, Dalton. Trans., 2015, 44, 15324-15333.

T. Devic and C. Serre, Chem. Soc. Rev., 2014, 43, 6097-6115. R. R. Haikal, C. Hua, J. J. Perry, D. O’Nolan, I. Syed, A. Kumar, A. H. Chester, M. J. Zaworotko, M. H. Yacoub and M. H. Alkordi, ACS Appl. Mater. Int., 2017, 9, 43520-43528.

E. D. Bloch, D. Britt, C. Lee, C. J. Doonan, F. J. Uribe-Romo, H. Furukawa, J. R. Long and O. M. Yaghi, J. Am. Chem. Soc., 2010, 132, 14382-14384.

S. Diring, A. Carne-Sanchez, J. Zhang, S. Ikemura, C. Kim, H. Inaba, S. Kitagawa and S. Furukawa, Chem. Sci., 2017, 8, 23812386.

T. Ueno, Chem. Eur. J., 2013, 19, 9096-9102.

T. O. Yeates and J. E. Padilla, Curr. Opin. Struct. Biol., 2002, 12, 464-470.

Y.-T. Lai, E. Reading, G. L. Hura, K.-L. Tsai, A. Laganowsky, F. J. Asturias, J. A. Tainer, C. V. Robinson and T. O. Yeates, Nat. Chem., 2014, 6, 1065. 

Bernardes, C. C. Romão and M. J. Romão, J. Am. Chem. Soc., 2011, 133, 1192-1195.

118. M. F. A. Santos, J. D. Seixas, A. C. Coelho, A. Mukhopadhyay, P. M. Reis, M. J. Romão, C. C. Romão and T. Santos-Silva, J. Inorg. Biochem., 2012, 117, 285-291.

119. K. Fujita, Y. Tanaka, T. Sho, S. Ozeki, S. Abe, T. Hikage, T. Kuchimaru, S. Kizaka-Kondoh and T. Ueno, J. Am. Chem. Soc., 2014, 136, 16902-16908.

120. H. Tabe, K. Fujita, S. Abe, M. Tsujimoto, T. Kuchimaru, S. KizakaKondoh, M. Takano, S. Kitagawa and T. Ueno, Inorg. Chem., 2015, 54, 215-220

121. K. Fujita, Y. Tanaka, S. Abe and T. Ueno, Angew. Chem. Int. Ed. 2016, 55, 1056-1060.

122. A. Carné-Sánchez, G. A. Craig, P. Larpent, T. Hirose, M. Higuchi, S. Kitagawa, K. Matsuda, K. Urayama and S. Furukawa, Nat. Commun., 2018, 9, 2506.

123. N. Giri, M. G. Del Pópolo, G. Melaugh, R. L. Greenaway, K. Rätzke, T. Koschine, L. Pison, M. F. C. Gomes, A. I. Cooper and S. L. James, Nature, 2015, 527, 216-220.

124. R. Gaillac, P. Pullumbi, K. A. Beyer, K. W. Chapman, D. A. Keen, T. D. Bennett and F.-X. Coudert, Nat. Mater., 2017, 16, 1149-1154

125. Y. Hara, K. Kanamori and K. Nakanishi, Angew. Chem. Int. Ed., 2019, 58, 19047-19053. 